Atıf: Yılmaz, E. (2021). Yüksek Çözünürlüklü ERA-Interim ve HadGEM2-CC Model Verilerine Göre Türkiye'nin Güncel ve Gelecekteki Holdridge Ekolojik Bölgeleri, Coğrafi Bilimler Dergisi/ Turkish Journal of Geographical Sciences, 19(1), 29-60, doi: 10.33688/aucbd.778259.

Coğrafi Bilimler Dergisi

Turkish Journal of Geographical Sciences

e-ISSN:1308-9765

\title{
Yüksek Çözünürlüklü ERA-Interim ve HadGEM2-CC Model Verilerine Göre Türkiye'nin Güncel ve Gelecekteki Holdridge Ekolojik Bölgeleri
}

\author{
Current and Future Holdridge Ecological Zones for Turkey Using High \\ Resolution ERA-Interim and HadGEM2-CC Model Data
}

Erkan Yilmaz ${ }^{* a}$

\begin{tabular}{l} 
Makale Bilgisi \\
\hline Araştırma Makalesi \\
\hline DOI: \\
10.33688/aucbd.778259 \\
\hline Makale Geçmişi: \\
Geliş: 21.11 .2020 \\
Kabul: 08.01.2021 \\
\hline Anahtar Kelimeler: \\
Holdridge Ekolojik Bölgeleri \\
Türkiye Biyomları \\
İklim Değişikliği \\
HadGEM2-CC Verileri \\
ERA-Interim Verileri \\
\end{tabular}

Article Info

\begin{tabular}{l}
\hline Research Article \\
\hline DOI: \\
10.33688/aucbd.778259 \\
\hline Article History: \\
Received: 21.11 .2020 \\
Accepted: 08.01.2021 \\
\hline Keywords: \\
Holdridge Ecological Zones \\
Biomes of Turkey \\
Climate Change \\
HadGEM2-CC Model Data \\
ERA-Interim Data
\end{tabular}

$\ddot{O} z$

Holdridge ekolojik bölgeleri (HEB), iklim sinıflandırma amacıyla kullanılmakta, ayrıca biyom tanımlaması sunmaktadır. Bu çalışmada yüksek çözünürlüklü ERA-Interim ve gelecek durumu yansitan HadGEM2-CC modeli verileri kullanılarak, Türkiye'nin güncel, 2041-2060 ve 2061-2080 dönemleri içi HEB ve bu dönemlere ait tümleşik HEB sinırları oluşturulmuştur. Elde edilen sonuçlara göre 2041-2080 döneminde Türkiye'de alçak irtifa ve dağönü kuşakları genişlerken dăglık, yarı alpin ve alpin sahaların daralmakta karlı sahalar ise neredeyse ortadan kalkmaktadır. Türkiye'de 2041-2060 döneminde kurak sahalar ortaya çıkmakta, yarı kurak ve yarı nemli sahalar artmakta, nemli, çok nemli, aşırı nemli ve yarı doygun sahalar ise daralmaktadır. Günümüzde Türkiye'de çöl çalılıklarl, dikenli çalılıklar, dikenli stepler, stepler, kurak ormanlar, nemli ormanlar, islak ormanlar, yă̆mur ormanları, tundralar ve soğuk çöl biyomları ile buzul alanları bulunmaktadır. 2041-2060 döneminde çok kurak orman biyomu ortaya çıkarken, 2061-2080 döneminde buzul alanları ortadan kalkmaktadır. Çalışmada ayrıca HEB sınıflarının belirlenmesi pratik hale getiren bir yöntem gelişstirilmiştir.

\footnotetext{
*Sorumlu Yazar/Corresponding Author: eryilmaz@ankara.edu.tr

a Ankara Üniversitesi, Coğrafya Bölümü, Ankara/Türkiye, http://orcid.org/ 0000-0002-3821-3648.
} 


\section{Giriş}

Küresel çapta kullanılan birçok iklim sınıflandırması bulunmakta, bunlar arasında KöppenGeiger (1954), Thornthwaite (1948), Trewarta (1968), Holdridge (1947) siniflandırmalar1 yer almaktadır. Farklı yöntemlerle uygulanan bu sınıflandırmaların her birinin kullanım alanları birbirinden farklılık olmakta, küresel ölçekteki sınıflandırmalarında Köppen-Geiger (Kottek vd., 2006; Peel, Finlayson ve Mcmahon, 2007) daha fazla kullanılırken, daha küçük sahalar ve özellikle hidrografya ile ilgili çalışmalarda Thornthwaite yöntemi tercih edilmektedir. Bu sınıflandırmalar, genel olarak, sıcaklık ve yağış değişkenleri ile üretilmekte, sonuçları ise sıcaklık, nemlilik, mevsimsel değişkenlik açısından ortaya koyulmaktadır. Holdridge sınıflandırmasına göre de ekolojik bölgeler ve kuşaklar elde edilmekte, diğerlerinden farklı olarak bu sinıflamada biyom tanımlaması da yer almaktadır. $\mathrm{Bu}$ türden bir tanımlama Erinç yağış etkinlik sınıflandırmasında (Erinç, 1965) bulunsa da Holdridge biyomları daha ayrintılidir.

Türkiye'nin iklim bölgeleri ile ilgili çok sayıda çalışma bulunmakta, bunlar arasında Thornthwaite (Erinç, 1949; Şensoy ve Ulupınar, 2015; Yılmaz ve Çiçek, 2016), Köppen (Yılmaz ve Çiçek, 2018), Erinç (Güngör, 2019; Şensoy ve Ulupınar, 2015), De Martonne (Güngör, 2019; Şensoy ve Ulupınar, 2015), Aydeniz (Güngör, 2019), Peltier (Gönençgil ve Sarıül, 2018) ve Sezer iklim sınıflandırmaları (Güngör, 2019; Sezer, 1988) bulunmaktadır. Türkiye'de Holdridge ekolojik bölgeleri (HEB) ile ilgili çalışmalar da yapılmış (Tatli ve Dalfes, 2016; Tatlı, 2017; Tekin, Tatlı ve Koç, 2018), bu araştırmalar istasyon tabanlı kalmış, bölge sınırları tam olarak belirlenmemiş̧ir. Küresel ölçekte de HEB sınırları belirlenmiş olmasına rağmen (Leemans, 1990), bu sınırların ayrıntısı düşük, Türkiye'yi temsil etme kabiliyeti azdır.

Küresel iklim modelleri ile yer yüzeyi ve atmosfer katları belli kurallara göre modellenerek, karbondioksit salım senaryolarına göre geleceğe dair öngörüler elde edilmekte, bu öngörüler sayesinde farklı iklim elemanlarına ait değerler belirlenerek, gelecekteki olası ortam koşulları ortaya koyulabilmektedir (Kattsov, vd., 2013). Bu modellere ait öngörüler, düşük çözünürlükte oldukları için, ölçek küçültme yöntemi uygulanarak bölgesel, daha ayrıntılı sonuçlar elde edilebilmektedir. Türkiye için de çeşitli iklim modeli sonuçları değerlendirilmiş, özellikle mevsimsel yağış ve sıcaklık koşullarındaki değişimler incelenmiştir (Demir, K1lı̧ ve Çoşkun, 2008; Gürkan, vd., 2016; Önol ve Semazzi, 2009; Özturk, vd., 2012). Yine bu modellere bağlı olarak, akımlarda oluşabilecek farklılıklar (Bozkurt ve Sen, 2013), kültür bitkilerinin (Baydar ve Kanber, 2012; Deveci, Konukcu ve Altürk, 2019; Kapur, Koç ve Özekici, 2012; Ustaoglu ve Karaca, 2014) ve doğal bitki örtüsü yaşam alanlarında oluşabilecek değişimler (Arslan ve Örücü, 2019; Çoban, Örücü ve Arslan, 2020; Mert, vd., 2016; Sarikaya, Karaceylan ve Sen, 2018; Walas, vd., 2019) incelenmiştir. Bu tür çalışmalar ya bölgesel ölçekte kalmış ya da tek bir canlı ortamına yönelik değişimler araştırılmış, Türkiye'nin geneline yayılan bir ortam değişim çalışması yapılmamıştır.

Holdridge ekolojik bölgeleri, yıllık toplam evapotranspirasyon miktarının yıllık toplam yağışa oranlanması ile elde edilen bir sistemde, biyomların tanımlanmasını sağlamakta, ortam değişimini iyi göstermektedir. Türkiye'nin HEB sınırlarının belirlenmesi ve bu sınırlarda iklim değişikliği ile 
oluşabilecek farklılıkların belirlenmesi, başta biyoçeşitlilik olmak üzere tarımsal, hidrografik, ormancılık, coğrafi ve bölgesel planlamalar için önemli bir referans noktası oluşturacaktır.

Bu çalışmada, Karger vd. (2017) tarafından küresel ölçekte üretilen aylık toplam yağış ve aylık ortalama sıcaklık verileri kullanılarak, Türkiye'nin güncel HEB sınırları belirlenmiştir. Çalışmada, yaklaşık 1 km'lik veri seti kullanılmış, Türkiye 800 bin nokta ile temsil edilmiş, HEB yükselti ekolojik katları, nemlilik bölgeleri ve biyom sınırları oluşturulmuş, ayrıca bu sınırlar birleştirilerek tümleşik HEB bölgeleri elde edilmiştir. Çalışmada hem 1979-2013 verileri kullanılarak güncel bölgeler elde edilmiş hem de HadGEM2-CC modeli 4.5 senaryosuna bağlı olarak üretilen 1 km çözünürlüklü verilerle, 2041 2060 ve 2061-2080 dönemlerine ait olası HEB sınırları oluşturularak güncel sınırlar ile karşılaştırmaları yapılmıştır. Çalışmanın hem Türkiye iklim literatürüne hem de iklim değişikliğine uyum politikalarına katkı sağlaması amaçlanmıştır. Çalışmada ayrıca HEB yönteminin kullanımını pratik hale getiren bir teknik geliştirilmiştir.

\section{Veri ve Yöntem}

\subsection{Veri}

Küresel ölçekte yüksek çözünürlüklü klimatolojik veri üretimi Hijmans vd. (2005) ile Fick ve Hijmans (2017) tarafından yapılmış, Türkiye için de iklim sınıflandırmaları çalışmalarında kullanılmıştır (Yılmaz ve Çiçek, 2016, 2018). Bu veriler, kullanılabilir olmasına rağmen, özellikle Tuz Gölü çevresi ile Kuzey Ege-Güney Marmara'yı iyi yansıtmadığı yazarlarca da belirtilmiştir. ECMWF tarafından üretilen (Dee vd., 2011) ERA-Interim yapılandırılmış verilerinin (reanalysis data) çözünürlükleri Karger vd. (2017) tarafından belli yöntemlerle artırılmış, http://chelsa-climate.org sitesinden indirilebilir olarak sunulmuştur. Verilerin incelenmesi sonucunda, Türkiye için yukarıda belirtilen sahaları Fick ve Hijmans (2017) verilerine göre daha iyi temsil ettiği anlaşılmış, çalışmada bu veriler kullanılmıştır. Karger vd. (2017) ERA-Interim yapılandırılmış verilerinin yanında farklı iklim modelleri ile üretilen öngörü verilerinin de çözünürlüklerini artırmış, güncel verilerin gelecek ile karşılaştırılmasına imkân sağlamıştır. Çalışmada gelecek dönemi yansıtması amacıyla, Türkiye'de sıklıkla kullanılan HadGEM2-ES modeli (Gorguner, Kavvas ve Ishida, 2019; Hepbilgin ve Koç, 2017; Turp, vd., 2014) verilerinin kullanılması istenmiş, bu modele ait verilerin çözünürlüklerinin artırılmadığı görülmüş, bunun yerine aynı model grubundan gelen HadGEM2-CC modeli 2041-2060 ve 2061-2080 dönemi verileri analiz edilmiştir. İklim modellerinde farklı emisyon senaryoları kullanılarak öngörüler yapılmakta, bu çalışmada ortalama bir emisyon salımı öngören RC4,5 standartlarına göre oluşturulmuş iklim modeli verileri kullanılmıştır.

Karger vd. (2017) tarafindan üretilen veriler konumsal olarak yaklaşı1k $1 \mathrm{~km}$ (30 saniye) çözünürlüğe sahiptir. Veriler, Albers çift standartlı alan koruyan projeksiyona dönüştürülmüş, bu şekilde metrik sisteme geçilmiştir. Bu şekilde Türkiye için 800 bini aşan noktaya ait güncel (1979-2013) ve gelecek dönemi yansıtan veri setleri oluşturulmuştur.

Elde edilen model verilerinde Türkiye'de 1979-2013 yılları ortalamalarına göre, yıllık ortalama sıcaklık -9.2 (Ağrı Dağı zirvesi) ile $20.5^{\circ} \mathrm{C}$ (Anamur kıyıları) arasında değişmektedir (Şekil 1a). HadGEM2-CC model verilerinde 2041-2060 yılları arasında ortalama sıcaklıklar tüm Türkiye'de günümüze göre artmakta, en yüksek artışlar, güneydoğu ile kuzeybatıda, en düşük artışlar ise güneybatı 
ile Karadeniz kıyılarında görülmektedir (Şekil 1b). 2061-2080 döneminde sıcaklık artışı yükselerek, günümüz ortalamalarına göre 2.2 ile $3.1^{\circ} \mathrm{C}$ daha yüksek olmakta, sıcaklık artma bölgesi kuzeydoğuya doğru genişlemektedir (Şekil 1c).
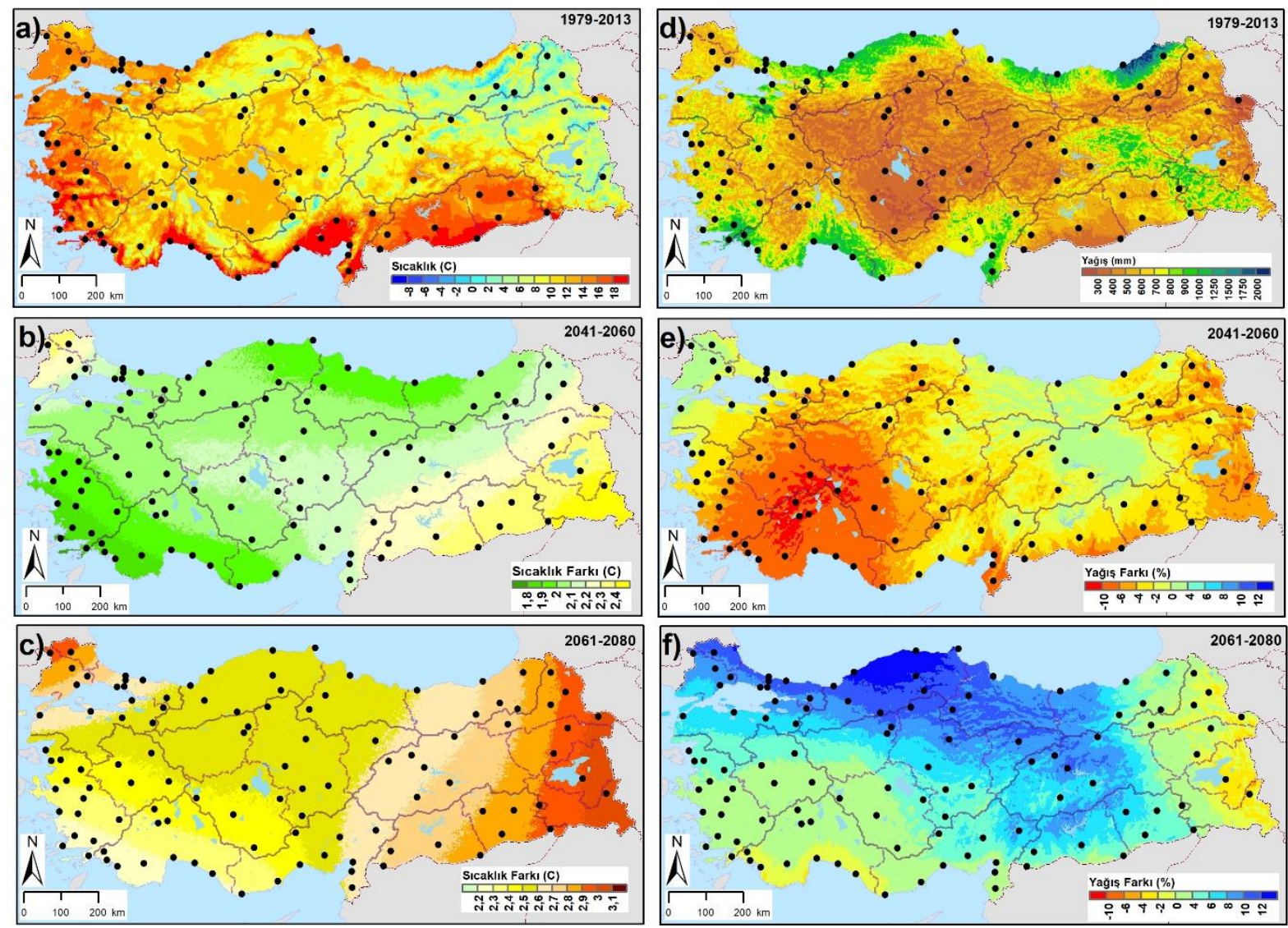

Şekil 1. Çalıșmada kullanılan veriler a) 1979-2013 dönemi yıllık ortalama sıcaklık, b) 2041-2060 ve 1979-2013 dönemi yıllık ortalama sıcaklık fark1), c) 2061-2080 ve 1979-2013 dönemi yıllık ortalama sıcaklık fark1), d) 1979-2013 dönemi y1llık ortalama toplam yağış, e) 2041-2060 ve 1979-2013 dönemi yıllık toplam yağış farkı (\%), f) 2061-2080 ve 1979-2013 dönemi y1llık toplam yağış farkı (\%).

ERA-Interim verilerine göre 1979-2013 yılları arasındaki yıllık toplam yă̆ışlar ise 214 (Iğdır çevresi) ile $2884 \mathrm{~mm}$ (Hopa güneyi-Balık Dağı) arasında değişmekte, en yüksek yă̆ışlar Doğu Karadeniz Dağları'nda, en düşük yağışlar ise Konya Havzası'nda görülmektedir (Şekil 1d). HadGEM2CC model verilerinde 2041-2060 döneminde, yıllık toplam yağışlar \% -12 ile 4 arasında değişmekte, Türkiye'nin güneybatısında \% 10'u aşan yağış azalmaları, sadece Orta Karadeniz ve Yukarı Fırat bölümlerinde \% 4'e yaklaşan yağış artışları görülmektedir (Şekil 1e). 2061-2080 döneminde günümüze göre Türkiye'nin doğu sınırı ve çevresi ile güneybatısı haricindeki yerlerde yağışlar artmaktadır. Karadeniz ve özellikle Batı Karadeniz Bölümü’ndeki artışlar \% 10’u aşmaktadır (Şekil 1f).

\subsection{Yöntem}

Holdridge ekolojik bölgelerinin oluşturulması için, yıllık toplam yağıŞ (YTY), biyolojik sıcaklık (BS) ve potansiyel evapotranspirasyon oranı (PEO) kullanılmaktadır (Holdridge, 1947). Bu çalışmada, kullanılan her nokta için önce aylık BS değerleri üretilmiş bu işlem esnasında eşitlik 1 kullanılmıştır. 


$$
B S_{a}=\left[\begin{array}{ll}
S_{o} \leq 0 & ; 0 \\
S_{o}>0 \text { ve } S_{o}<30 & ; S_{o} \\
S_{o} \geq 30 & ; 30
\end{array}\right]
$$

Aylık biyolojik sıcaklıkların toplanması ve 12'ye bölünmesi ile yıllık ortalama biyolojik sıcaklıklar (Eşitlik 2) ve eşitlik 3 kullanılarak PEO değerleri belirlenmiştir.

$$
\begin{aligned}
& B S_{y}=\frac{1}{12} \sum B S_{a} \\
& \mathrm{PEO}=\frac{B S_{y} * 58,93}{Y T Y}
\end{aligned}
$$

HEB sınıflaması, YTY ve PEO değerinin üçgen grafiğe yerleştirilmesi ile yapılmaktadır (Şekil 2). Grafikte, YTY ve PEO verileri logaritmik olarak verilmekte, bir sahaya-meteoroloji istasyonuna ait veriler grafiğe yerleştirilerek tanımlama yapılmaktadır. Çalışmada 2,5 milyona yakın nokta verisi kullanılmış, her bir nokta verisinin bu grafiğe yerleştirilerek ekolojik bölgenin belirlenmesinin oldukça uzun zaman alacağı anlaşılmıştır. Bu amaçla üçgen grafik, sayısallaştırılmış, her noktası tanımlı bir haritaya çevrilmiştir.

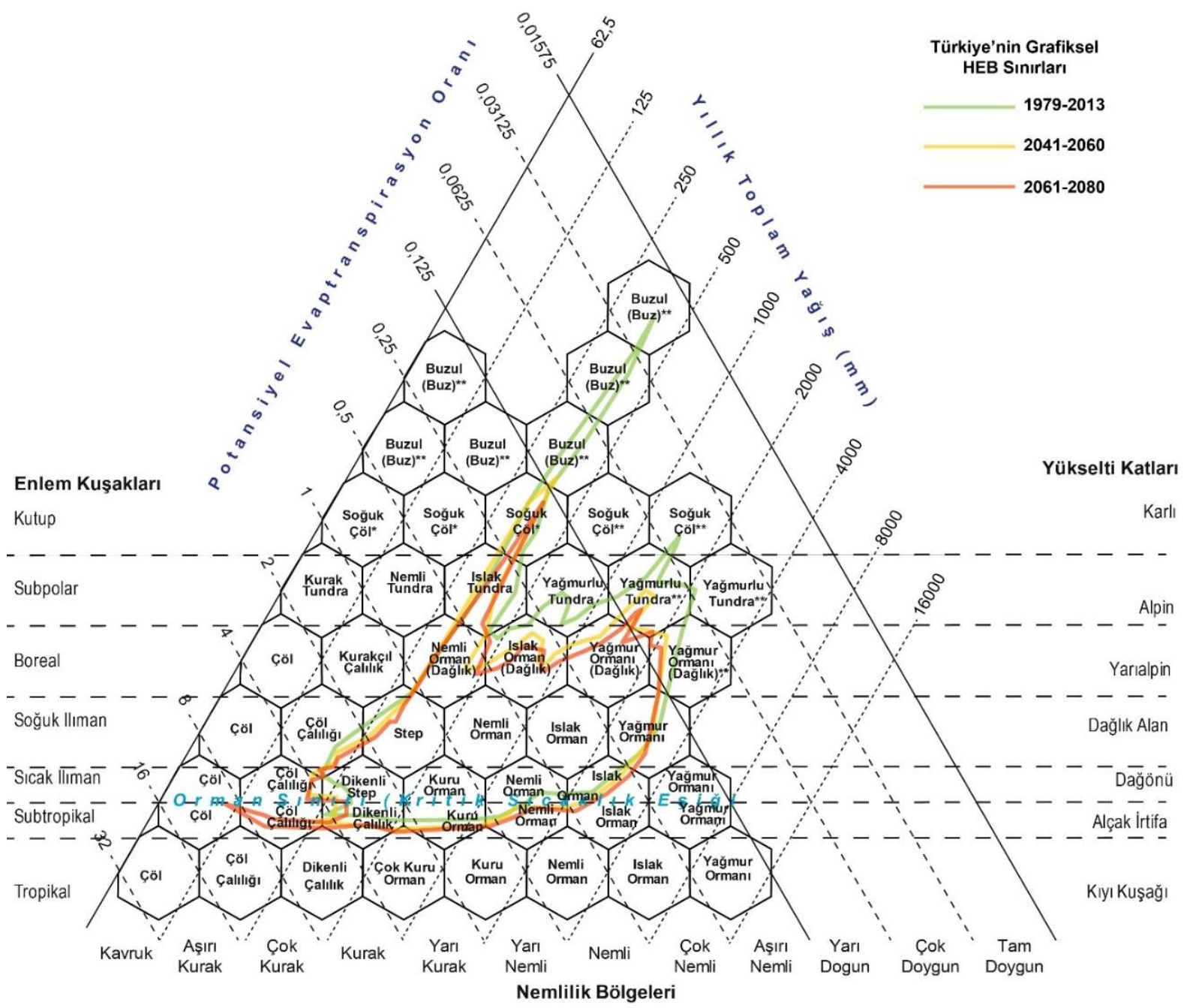

Şekil 2. Çalışmada HEB bölgelerinin belirlenmesi amacıyla kullanılan üçgen grafik (*Daha önce buz olarak çevrilmiş, bu çalışmada buzul olarak adlandırılmıştır; **Bu altıgenler bu çalışmada adlandırılmıştır.) 
Şekil 2'deki üçgen grafik, saatin tersi yönünde 150 derece döndürülmüş, bu sayede apsis (PEO) ve ordinat ekseni (YTY) kesişimi düzlemin 0,0 noktasına getirilmiş, PEO değeri X, YTY ise Y eksenini oluşturacak şekilde bir koordinat düzlemi oluşmuştur. Bu düzlem kullanılırken her iki değişkenin de 2 tabanında logaritması kullanılmış, fakat her iki değer için de 0'ın belirlenebilmesi için, $\log _{2}$ PEO - $\log _{2}$ 0,125 kullanılarak, PEO değeri 0,125 olan değerler X1=0 ile gösterilmiş, 0,25 PEO oranına sahip bir nokta ise $X 1=1$ ile gösterilmiştir. Benzer şekilde YTY değeri için $\log _{2}$ YTY- $\log _{2}(62,5)$ formülü uygulanarak, 62,5 mm yağışı olan bir yer için Y1=0, YTY değeri 125 olan bir yer ise Y1=1 değeri ile gösterilecek şekilde düzenlenmiştir. Devamında, her noktanın bulunduğu yerin tespiti için, 60 derecelik bir kayma zemini oluşturulmuş, her $\mathrm{X}$ değeri için $\mathrm{X}=\sin 30 * \mathrm{Y} 1+\mathrm{X} 1$, her $\mathrm{Y}$ değeri için $\mathrm{Y}=\cos 30 * \mathrm{Y} 1$ işlemleri yapılmış, her nokta-meteoroloji istasyonuna ait Holdridge koordinatları belirlenebilmiştir. $\mathrm{Bu}$ koordinat sisteminde, referans noktalara göre, biyom, yükseklik ekolojik katları ve nemlilik sınıfları da ayrı ayrı alanlarla tanımlandığından, koordinat düzlemine yerleştirilen noktalar, konumsal eşleşme (spatial join) kullanılarak, her nokta için HEB tanımlamaları yapılmış ve işlemler tamamlanmıştır.

Holdridge ekolojik bölgeleri ilk olarak Amerika Birleşik Devletleri için hazırlanmış ve Kuzey Amerika'daki ekolojik şartlar değerlendirilerek tanımlamalar gerçekleştirilmiş̧ir. İlk yapıldığı dönem bazı altıgenler tanımlanmamış (Holdridge, 1947; Holdridge ve Joseph, 1967), daha sonra bazıları adlandırılmıştır (Tatli ve Dalfes, 2016). Bu çalışmada elde edilen sonuçlar, mevcut grafikte tanımlanmamış sahalarda belirlenmiş, bu sahalar için yeni altıgen alan tanımlamaları yapılmıştır. Ayrıca tanımlamaların bir kısmının Türkçeye çevirisi, iki saha arasındaki bitki ve hayvan topluluklarının aynı olmaması ve biyomların farklı türlerle temsil edilmesi nedeniyle mümkün olmamaktadır. Bu çalışmada daha önceki çalışmalardan Tekin vd. (2018) ve Atalay (2008)'den yararlanılarak terimler çevrilmiş, bazılarının çevirisi ise yazar tarafından yapılmıştır.

Çalışmada üretilen veri ve yöntem dosyaları, http://geography.humanity.ankara.edu.tr/turkiyeiklim-arastirmalari/ adresinde kullanıcılara sunulmuştur.

\section{Bulgular ve Tartışma}

\subsection{HEB Sınıflamasına Göre Türkiye'nin Enlem ve Yükseklik Kuşakları}

HEB sınıflandırmasında, enlem ve yükselti artışı ekolojik olarak benzer etki yapmakta aynı BS eşik değerlerine göre belirlenmektedir. Fakat, birim enlem ve birim yükselti değişiminden kaynaklanan etki birbirinden farklı olmakta ve her bölge için değişmektedir. Bu açıdan burada işlenecek enlem ve yükseklik kuşakları Türkiye için daha çok yükselti kuşaklarını ifade etmekte ve Türkiye'de 6 farklı HEB yükselti ekolojik kuşağı yer almaktadır. Bunlar, alçak irtifa, dağönü, dağlık alan, yarıalpin, alpin ve karlı kat olarak sıralanmaktadır.

Alçak irtifa kuşağ1, 1979-2013 döneminde, Güneydoğu Anadolu Bölgesinin alçak kesimlerinde görülmekte, 2041-2060 ve 2061-2080 dönemlerinde bölgenin tamamına yakınını kaplamakta, sadece Karacadağ çevresi dağönü kuşağında kalmaktadır (Şekil 4). Bu kuşak, ERA-Interim güncel ortalamalarına göre Akdeniz Bölgesinin kıyı kesiminde ve kıyı ovalarında dağılış göstermekte, HadGEM2-CC verilerine göre 2041-2060 ve 2061-2080 dönemlerinde alanını genişletse de bu genişleme özellikle akarsu vadileri (Göksu, Aksu, Ceyhan, Seyhan) boyunca olmakta, kıyılarda ise 
eğimin yüksek olması nedeniyle ancak dikey yönde değişim görülmekte, bu da genişleme oranını düşürmektedir. Güncel ortalamalarda Ege Bölgesinin grabenleri ve bu grabenlere açılan vadi tabanlarında da hâkim olan alçak irtifa kuşağı, 2041-2060 ve sonraki dönemlerde bu vadiler boyunca ilerlemekte, Kıyı Ege Bölümünün yüksek kısımları haricinde tamamını, İç Ege Bölümünün ise Kıyı Ege Bölümüne komşu, alçak ovalarını-platolarını kaplamaktadır.

1979-2013 ortalamalarına göre Türkiye'nin \% 7'sinden fazlasını kaplayan alçak irtifa kuşağı (Çizelge 1), Marmara ve Karadeniz Bölgelerinde görülmemektedir. Bu kuşak, HadGEM2-CC model verilerine göre 2041-2060 ve 2061-2081 dönemlerinde Marmara Bölgesinin yüksek dağlı alanlar1 haricinde tamamına yayılmakta, Karadeniz kıyılarında görülmeye başlamakta, Bafra ve Çarşamba deltalarında hâkim olmaktadır. Güncel ortalamalara göre Türkiye'de 58 bin $\mathrm{km}^{2}$ alan kaplayan alçak

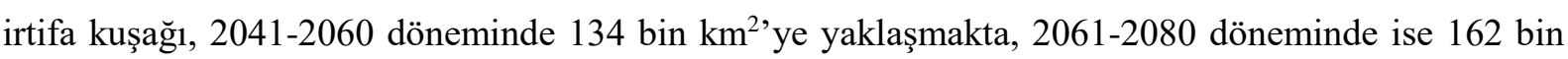
$\mathrm{km}^{2}$ ' yi aşarak, Türkiye'nin beşte birinden fazlasını oluşturmaktadır (Şekil 3, Şekil 4).

Çizelge 1. 1979-2013 ortalamalarına göre (ERA-Interim) Türkiye coğrafi bölgelerinde yükselti-ekolojik katları.

\begin{tabular}{|c|c|c|c|c|c|c|c|c|}
\hline Yükselti Katları & KB & MB & EB & $\mathbf{A B}$ & $\begin{array}{l}\mathbf{I} A B \\
\end{array}$ & DAB & GAB & Toplam \\
\hline Alçak İrtifa- Subtropikal K. & 0,0 & 0,0 & 15809,6 & 26235,8 & 0,0 & 181,7 & 15947,2 & 58174,4 \\
\hline \multirow{2}{*}{$\begin{array}{l}\text { Türkiye Oranı (\%) } \\
\text { Bölgesel Oran (\%) }\end{array}$} & 0,00 & 0,00 & 27,18 & 45,10 & 0,00 & 0,31 & 27,41 & 100,00 \\
\hline & 0,00 & 0,00 & 19,26 & 23,74 & 0,00 & 0,11 & 25,93 & 7,46 \\
\hline \multirow{3}{*}{$\begin{array}{r}\text { Dağönü-Sıcak Ilıman Kuşak } \\
\text { Türkiye Oranı (\%) } \\
\text { Bölgesel Oran (\%) }\end{array}$} & 25845,3 & 55784,9 & 41152,5 & 38330,2 & 54114,0 & 22947,1 & 44216,2 & 282390,2 \\
\hline & 9,15 & 19,75 & 14,57 & 13,57 & 19,16 & 8,13 & 15,66 & 100,00 \\
\hline & 19,27 & 89,33 & 50,14 & 34,68 & 33,68 & 13,59 & 71,90 & 36,20 \\
\hline \multirow{3}{*}{$\begin{array}{r}\text { Dağlık-Soğuk Ilıman Kuşak } \\
\text { Türkiye Oranı (\%) } \\
\text { Bölgesel Oran (\%) }\end{array}$} & 95355,0 & 6556,5 & 25093,2 & 44448,9 & 105913,3 & 128881,7 & 1333,8 & 407582,4 \\
\hline & 23,40 & 1,61 & 6,16 & 10,91 & 25,99 & 31,62 & 0,33 & 100,00 \\
\hline & 71,10 & 10,50 & 30,57 & 40,22 & 65,92 & 76,33 & 2,17 & 52,24 \\
\hline \multirow{3}{*}{$\begin{array}{r}\text { Yarıalpin-Boreal Kuşak } \\
\text { Türkiye Oranı (\%) } \\
\text { Bölgesel Oran (\%) }\end{array}$} & 12199,8 & 110,0 & 20,0 & 1476,0 & 623,3 & 16754,1 & 0,2 & 31183,4 \\
\hline & 39,12 & 0,35 & 0,06 & 4,73 & 2,00 & 53,73 & 0,00 & 100,00 \\
\hline & 9,10 & 0,18 & 0,02 & 1,34 & 0,39 & 9,92 & 0,00 & 4,00 \\
\hline \multirow{3}{*}{$\begin{array}{r}\text { Alpin-Kutupçevresi Kuşak } \\
\text { Türkiye Oranı (\%) } \\
\text { Bölgesel Oran (\%) }\end{array}$} & 715,6 & 0,0 & 0,0 & 27,0 & 7,0 & 70,9 & 0,0 & 820,5 \\
\hline & 87,21 & 0,00 & 0,00 & 3,29 & 0,85 & 8,65 & 0,00 & 100,00 \\
\hline & 0,53 & 0,00 & 0,00 & 0,02 & 0,00 & 0,04 & 0,00 & 0,11 \\
\hline \multirow{3}{*}{$\begin{array}{l}\text { Karlı-Kutup Kuşağı } \\
\text { Türkiye Oranı (\%) } \\
\text { Bölgesel Oran (\%) }\end{array}$} & 3,0 & 0,0 & 0,0 & 0,0 & 0,0 & 21,0 & 0,0 & 24,0 \\
\hline & 12,49 & 0,00 & 0,00 & 0,00 & 0,00 & 87,51 & 0,00 & 100,00 \\
\hline & 0,00 & 0,00 & 0,00 & 0,00 & 0,00 & 0,01 & 0,00 & 0,00 \\
\hline \multirow[t]{2}{*}{ Toplam } & 134118,7 & 62451,4 & 82075,3 & 110517,8 & 160657,6 & 168856,7 & 61497,4 & 780174,8 \\
\hline & 17,19 & 8,00 & 10,52 & 14,17 & 20,59 & 21,64 & 7,88 & 100,00 \\
\hline
\end{tabular}

Kısaltmalar: KB-Karadeniz, MB-Marmara, EB-Ege, AB- Akdeniz, İAB-İç Anadolu, DAB-Doğu Anadolu, GAB-Güneydoğu Anadolu Bölgesini ifade etmektedir.

Dağönü kuşağı, günümüzde, alçak irtifa kuşağını çevreleyecek şekilde, Güneydoğu Anadolu, Akdeniz ve Ege Bölgelerinin büyük kısmını kaplamakta, Marmara Bölgesinin yüksek dağlık alanlar haricinde tamamında, Karadeniz kıyılarında, Yeşilırmak ve Kızılırmak vadilerinde, İç Anadolu Bölgesinin batı yarısında ve Yukarı Fırat Bölümünün depresyon alanlarında dağılış göstermektedir. Model verilerine göre bu kuşak, 2041-2060 ve 2061-2080 dönemlerinde genişlemekte, günümüzde 280 bin $\mathrm{km}^{2}$ 'yi aşarken (Çizelge 1), bu dönemlerde 370 bin $\mathrm{km}^{2}$ 'yi geçmekte, Türkiye'nin yarısına yakınını kaplamaktadır (Şekil 3). İklim modellerinden elde edilen sonuçlara göre dağönü kuşağı, İç Anadolu Bölgesinin Yukarı Kızılırmak Bölümü haricinde tamamında, İç Ege, Orta Karadeniz ve Yukarı Fırat Bölümüne hâkim yükselti-ekolojik kuşağı halini almaktadır (Şekil 4). Bu genişlemenin yanında, 
günümüzde Marmara Bölgesine hâkim olan dağönü kuşağı, iklim modeli sonuçlarına göre bölgede daralmakta, yerini alçak irtifa kuşağına bırakmaktadır.

1979-2013 ortalamalarına göre Türkiye'de en geniş alan kaplayan yükselti-ekoloji kuşağı dağl1k alandır (Çizelge 1) ve Doğu Anadolu Bölgesinin büyük bir bölümünde, Toros dağlık alanının yüksek kısımlarında, Karadeniz Bölgesinin kıyı kuşağı, ovaları ve yüksek kısımları haricinde kalan kesimlerinde ve İç Anadolu Bölgesi, İç Ege ve Yıldız Dağları Bölümünün yüksek kısımlarında hâkim durumdadır (Şekil 4). Dağlik alanlar, model verilerine göre 2041-2060 döneminde daralarak daha yükseklere doğru yer değiştirse de (Şekil 4) Türkiye'nin üçte birinden fazlasını kaplamaktadır (Şekil 3). 2060-2081 döneminde dağlik alanlar daralmaya devam etmekte, alanı 240 bin km²'nin altına inmektedir.

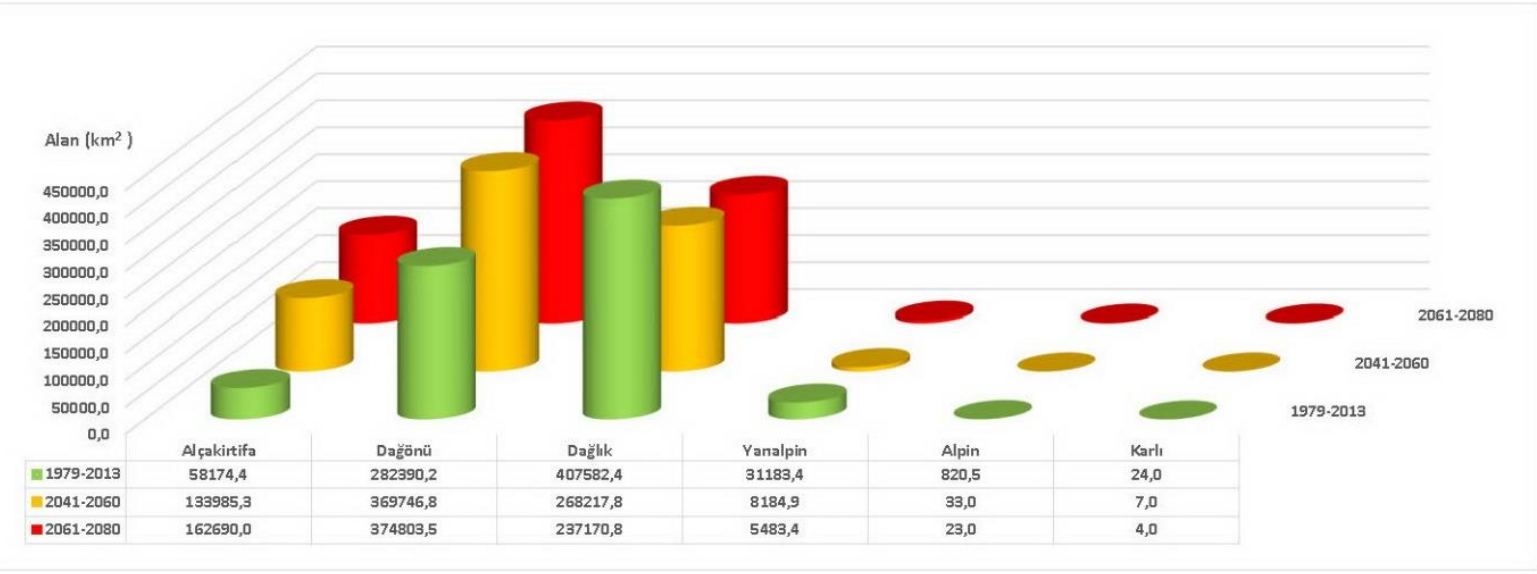

Şekil 3. HEB yükselti-enlem ekolojik kuşaklarının dönemlere göre alanları $\left(\mathrm{km}^{2}\right)$ ve değişimi (Grafik ölçeği logaritmiktir).

Dağlık kuşaktan daha yüksekte görülen yarıalpin kuşak günümüzde Türkiye'de 30 bin km²' den daha geniş alan kaplamakta (Çizelge 1), Ege ve Güneydoğu Anadolu Bölgesinde dar sahalarda görülse de tüm bölgelerde karşımıza çıkmaktadır. Bu kuşağın \% 90'ından fazlası, Doğu Anadolu ve Karadeniz Bölgesinin yüksek kısımlarında karşımıza çıkmaktadır. Alpin kat ise, Akdeniz, İç ve Doğu Anadolu Bölgesinde görülmekte, bu katın \% 87'si Karadeniz Bölgesinde yer almaktadır. Çayırlarla kaplı bu sahalar, orman üst sınırından daha yükseklerde yer almakta, kış boyu karla örtülmekte, vejetasyon faaliyetleri yazın devam ettirilebilmektedir. HadGEM2-CC model verilerine göre 2041-2060 dönemlerinde hem yarı alpin hem de alpin kuşak daralmaktadır (Şekil 4, Şekil 3). Yarıalpin kat 20612080 döneminde daralmaya devam etmekte ve 5 bin $\mathrm{km}^{2 `}$ den biraz geniş alana sahip olmakta, alpin kat ise $23 \mathrm{~km}^{2}$ alan kaplamaktadır. Bu dönemlerde alpin kat, yarıalpin kata dönüşmekte, yarıalpin katın daralması ise, sıcaklık artışına bağlı olarak yerini dağlık alana bırakmasından kaynaklanmaktadır.

Yükselti katlarından en dar alan kaplayan karlı kat Türkiye'de $24 \mathrm{~km}^{2}$ alan kaplamakta (Çizelge 1), sadece Ağrı Dağı zirvesi çevresinde tanımlanmaktadır (Şekil 4). Bu kat 2041-2060 döneminde 7, 2061-2080 döneminde 4 km² alana kadar daralmakta, görüldügü yükseklik artmaktadır. 

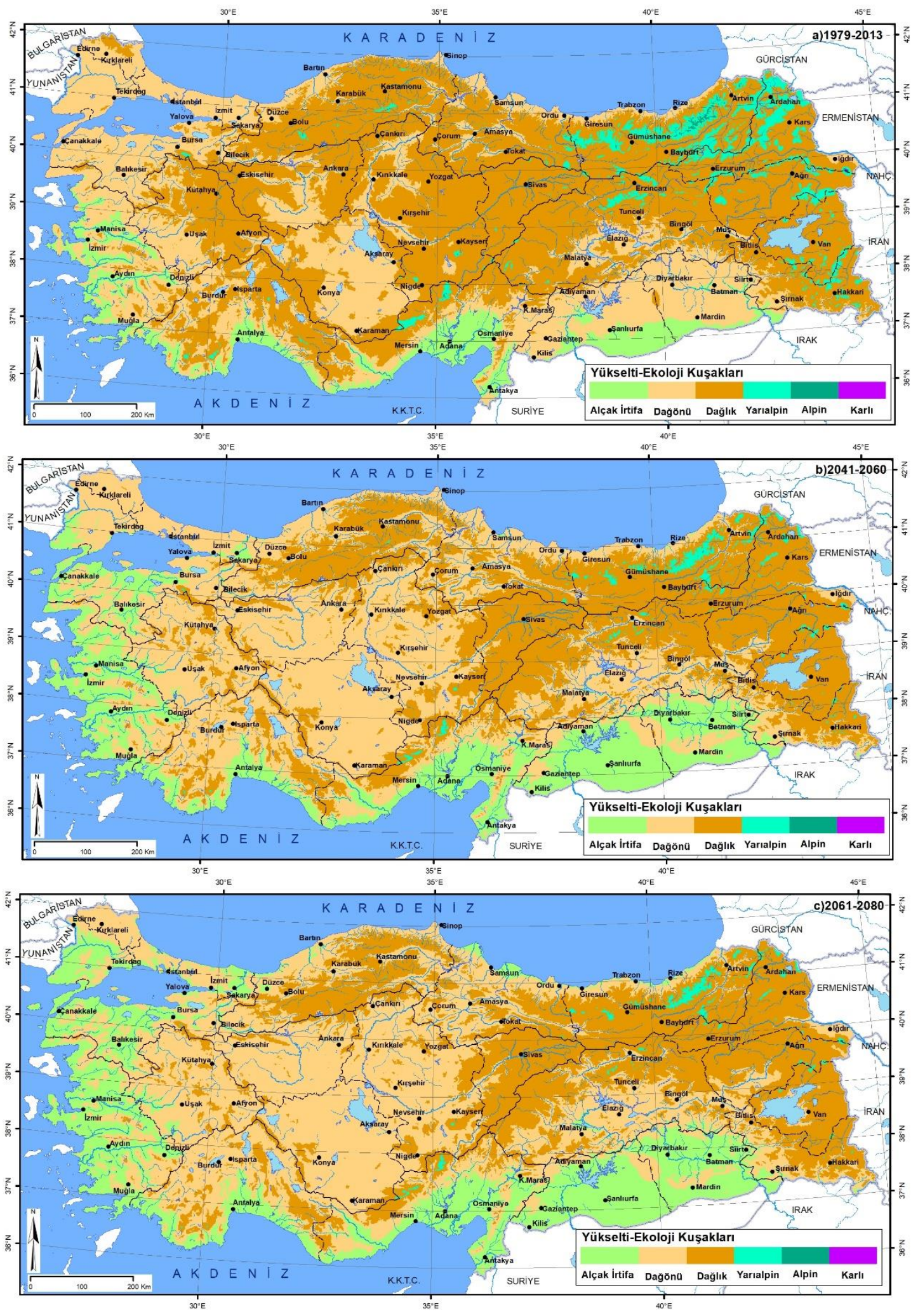

Şekil 4. Türkiye'nin Holdridge Yükselti Katları

HEB yükselti-ekolojik katları, BS ile belirlenmekte, BS ise buharlaşma kapasitesinin belirlenmesi amacıyla hesap edilmektedir. Bu nedenle BS, bir buharlaşma değişkeni niteliğindedir. 
Thornthwaite (1948) iklim sinıflandırmasında y1llik toplam evapotranspirasyon potansiyeli belirlenmekte, bu değer sıcaklık tesiri indisi olarak kullanılmakta ve sınıflandırma yapılmaktadır. $\mathrm{Bu}$ açıdan bakıldığında, HEB ve Thornthwaite sınıflandırma sitemlerinin birbirine benzediği anlaşılmakta, Türkiye için daha evvel yapılan Thornthwaite sıcaklık tesiri haritası (Yılmaz ve Çiçek, 2016) ile Holdridge yükselti ekolojik katları birbirine örtüşmekte (Örneğin 4. dereceden mezotermal alanlar alçak irtifa kuşağına denk gelmektedir), sınırlarda küçük değişiklikler görülmektedir. Bu farklılık da buharlaşmanın farklı yöntemle hesap edilmesinden, sınıflandırmada farklı eşik değerler kullanılmasından ve iki çalışmada farklı veri setlerinin kullanılmasından kaynaklanmaktadır.

\subsection{HEB Sınıflamasına Göre Türkiye’nin Nemlilik Bölgeleri ve Değişimi}

HEB nemlilik sınıfları, evapotranspirasyon-yağış oranına bağlı olarak oluşturulmaktadır. Evapotranspirasyon, sıcaklık artışına bağlı olarak arttığından, yüksek sıcaklık değerine sahip yerler yüksek yağış alsalar da kurak sınıfına dahil olabilmekte, bunun tersi olarak, soğuk bölgelerde buharlaşma düşük olduğundan, düşük yağış almaların rağmen nemli bir özellik gösterebilmektedir. 1979-2013 yılları ERA-Interim verilerine göre Türkiye'de HEB nemlilik sınıflarından, yarı kurak, yarı nemli, nemli, çok nemli, aşırı nemli ve yarı doygun, çok doygun ve tam doygun alanlar yer almakta, kurak saha bulunmamaktadır (Çizelge 2, Şekil 5). Buna rağmen, 2041-2060 ve 2061-2080 dönemlerinde kurak sahalar da görülmeye başlanmakta, yüksek doygun ve tam doygun sahalar ise ortadan kalkmaktadır (Şekil 5, Şekil 6).

Günümüz ortalamalarına göre Türkiye'de kurak sahalar görülmezken, model verilerine göre 2041'den sonra Güneydoğu Anadolu Bölgesi güneyi ile Iğdır Ovası'nda görülmeye başlamakta (Şekil 5), 2041-2060 döneminde $923 \mathrm{~km}^{2}$ alan kaplarken, 2061-2080 döneminde daralsa da $330 \mathrm{~km}^{2}$ 'den geniş sahalarda karşımıza çıkmaktadır (Şekil 6). Günümüzde Türkiye'nin yaklaşık \% 10'unu kaplayan yarı kurak sahaların (Çizelge 2), \% 81'i İç ve Güneydoğu Anadolu Bölgesinde (Şekil 5) yer almaktadır. Model verilerine göre bu sahalar 2041-2060 döneminde iki katına çıkmakta, 2061-2080 döneminde yağışı artan bölgelerde daralmakta yine de günümüze göre daha geniş alan kaplamaktadır. Yarı kurak sahalar genişlerken, yarı nemli bölgelerin yerini almaktadır.

Çizelge 2. 1979-2013 ortalamalarına göre (ERA-Interim) HEB nemlilik sınıflarının coğrafi bölgelere göre alanları ve oranları.

\begin{tabular}{|c|c|c|c|c|c|c|c|c|}
\hline Nem. Sinıfi & KB & MB & EB & $\mathbf{A B}$ & İAB & DAB & GAB & Toplam \\
\hline Yarı Kurak & 3624,1 & 225,8 & 2307,0 & 2610,8 & 44346,7 & 5261,4 & 17101,8 & 75477,7 \\
\hline Türkiye Oranı (\%) & 4,80 & 0,30 & 3,06 & 3,46 & 58,75 & 6,97 & 22,66 & 100,00 \\
\hline Bölgesel Oran (\%) & 2,70 & 0,36 & 2,81 & 2,36 & 27,60 & 3,12 & 27,81 & 9,67 \\
\hline Yarı Nemli & 45161,6 & 50548,0 & 62315,6 & 68675,0 & 104506,1 & 69729,1 & 42082,9 & 443018,2 \\
\hline Türkiye Oranı (\%) & 10,19 & 11,41 & 14,07 & 15,50 & 23,59 & 15,74 & 9,50 & 100,00 \\
\hline Bölgesel Oran (\%) & 33,67 & 80,94 & 75,92 & 62,14 & 65,05 & 41,29 & 68,43 & 56,78 \\
\hline Nemli & 64897,2 & 11279,2 & 17073,0 & 35116,0 & 11633,2 & 78828,3 & 2289,0 & 221116,0 \\
\hline Türkiye Oranı (\%) & 29,35 & 5,10 & 7,72 & 15,88 & 5,26 & 35,65 & 1,04 & 100,00 \\
\hline Bölgesel Oran (\%) & 48,39 & 18,06 & 20,80 & 31,77 & 7,24 & 46,68 & 3,72 & 28,34 \\
\hline Çok Nemli & 16497,5 & 354,8 & 375,2 & 4087,0 & 171,6 & 14856,3 & 23,7 & 36366,1 \\
\hline Türkiye Oranı (\%) & 45,36 & 0,98 & 1,03 & 11,24 & 0,47 & 40,85 & 0,07 & 100,00 \\
\hline Bölgesel Oran (\%) & 12,30 & 0,57 & 0,46 & 3,70 & 0,11 & 8,80 & 0,04 & 4,66 \\
\hline Aşırı Nemli & 3196,3 & 43,5 & 4,5 & 29,0 & 0,0 & 172,5 & 0,0 & 3445,8 \\
\hline Türkiye Oranı (\%) & 92,76 & 1,26 & 0,13 & 0,84 & 0,00 & 5,01 & 0,00 & 100,00 \\
\hline Bölgesel Oran (\%) & 2,38 & 0,07 & 0,01 & 0,03 & 0,00 & 0,10 & 0,00 & 0,44 \\
\hline Yarı Doygun & 736,0 & 0,0 & 0,0 & 0,0 & 0,0 & 7,0 & 0,0 & 743,0 \\
\hline
\end{tabular}




\begin{tabular}{lrrrrrrrr}
\hline \multicolumn{1}{c}{} & \multicolumn{1}{c}{0,00} & 0,00 & 0,00 & 0,94 & 0,00 & 100,00 \\
\hline Türkiye Oranı (\%) & 99,06 & 0,00 & 0,00 & 0,10 \\
\hline Bölgesel Oran (\%) & 0,55 & 0,00 & 0,00 & 0,00 & 0,00 & 0,00 & 0,00 & 7,0 \\
\hline Çok Doygun & 6,0 & 0,0 & 0,0 & 0,0 & 0,0 & 1,0 & 0,0 & 100,00 \\
\hline Türkiye Oranı (\%) & 85,70 & 0,00 & 0,00 & 0,00 & 0,00 & 14,30 & 0,00 & 0,00 \\
\hline Bölgesel Oran (\%) & 0,00 & 0,00 & 0,00 & 0,00 & 0,00 & 0,00 & 0,00 & 1,0 \\
\hline Tam Diygun & 0,0 & 0,0 & 0,0 & 0,0 & 0,0 & 1,0 & 0,0 & 100,00 \\
\hline Türkiye Oranı (\%) & 0,00 & 0,00 & 0,00 & 0,00 & 0,00 & 100,00 & 0,00 & 0,00 \\
\hline Bölgesel Oran (\%) & 0,00 & 0,00 & 0,00 & 0,00 & 0,00 & 0,00 & 0,00 & 780174,8 \\
\hline Toplam & 134118,7 & 62451,4 & 82075,3 & 110517,8 & 160657,6 & 168856,7 & 61497,4 & 780 \\
\hline Türkiye Oranı (\%) & 17,19 & 8,00 & 10,52 & 14,17 & 20,59 & 21,64 & 7,88 & 100,00 \\
\hline
\end{tabular}

ERA-Interim verilerine göre günümüzde Türkiye'nin \% 57'si yarı nemli sahalardan oluşmakta ve bu sahalar tüm bölgelerde bulunmaktadır. Yarı kurak alanları çevreleyen yarı nemli alanlar, Marmara Bölgesinin \% 81'ini, Ege Bölgesinin \% 76'sına yakınını, Akdeniz Bölgesinin \% 62, Güneydoğu Anadolu Bölgesinin \% 68'ini, İç Anadolu Bölgesinin ise \% 65'ten fazlasını kaplamaktadır. Türkiye genelinin de \% 57'sine yakını yarı nemli alanlardan oluşmaktadır. HadGEM2-CC verilerinde 2041-2060 ve 2061-2080 dönemlerinde günümüze göre genişleyen yarı nemli sahalar (Şekil 6), gerçekte yarı kurak sınırından daralmakta, nemli bölge sınırından ise genişlemekteyse de bu genişleme, yarı kurak sınırındaki daralmadan daha fazla olduğu için genel alanın genişlemesi şeklinde görülmektedir. Yarı nemli sahaların 2061-2080 döneminde genişlemesinde, yağış artışı da etkili olmaktadır. Burada, Holdridge yönteminin, sıcaklık artışına karşı duyarsız olması da ekilidir. Çünkü, $30^{\circ} \mathrm{C}$ daha yüksek sıcaklıkların tamamı $30^{\circ} \mathrm{C}$ gibi değerlendirilmekte, sıcaklık artsa da bunun buharlaşmaya etkisi bazı bölgelerde sabit olarak kalmakta, yağışın artması da nemlilik sınıfının değişmesini-kuraklaşmayı engellemektedir.

Günümüz ortalamalarına göre Türkiye'nin \% 28'i nemli alanlardan oluşmakta, bu alanların \% 36'sı Doğu Anadolu Bölgesinde, \% 29'u Karadeniz Bölgesinde, \% 16'sı ise Akdeniz Bölgesinde yer almaktadır (Çizelge 2). Dağlık alanların yüksek kesimlerinde karşımıza çıkan bu sahalar, Karadeniz Bölgesinde yılın tamamında, Akdeniz Bölgesinde kışın, Doğu Anadolu Bölgesinde ise bahar ve güz mevsimlerinde daha fazla yağış almaktadır. Nemli sahalar, model verilerine göre 2041-2060 döneminde daralarak 146 bin km² civarında, 2041-2060 döneminde ise genişleyerek 157 bin $\mathrm{km}^{2}$ alan kaplamaktadır (Şekil 6). Nemli alanlar, günümüzdeki orman sahaları ile büyük oranda örtüşmekte (OGM, 2012), EB, MB ve AB'deki orman alanlarının bir kısmı yarı nemli sahalar içerisinde yer almaktadır.

Çok nemli ve aşırı nemli sahalar Türkiye'nin \% 5'ini oluşturmakta, daha çok Karadeniz ve Doğu Anadolu Bölgesinin yüksek kesimlerinde dağılış göstermektedir. Hem çok hem de aşırı nemli sahalar, 2041-2060 döneminde daralmakta ve günümüzdeki alanlarının yarısından daha küçük alanda görülmektedir (Şekil 6). Bu sahalar 2061-2080 döneminde de daralmakta fakat daralma oranı düşük kalmaktadır. Çok ve aşırı nemli sahalar ile günümüzde eski buzul vadilerinin görüldüğü periglasyal sahalar özellikle Doğu Anadolu ve Karadeniz Bölgesinde büyük oranda örtüşmektedir (Sarıkaya, Çiner ve Zreda, 2011). Çok ve aşırı nemli sahaların bir kısmının Würm döneminde buzullaşma sahası olduğu ve buzul süreçlerinin hâkim olduğu anlaşılmaktadır (Çiner, 2003). 

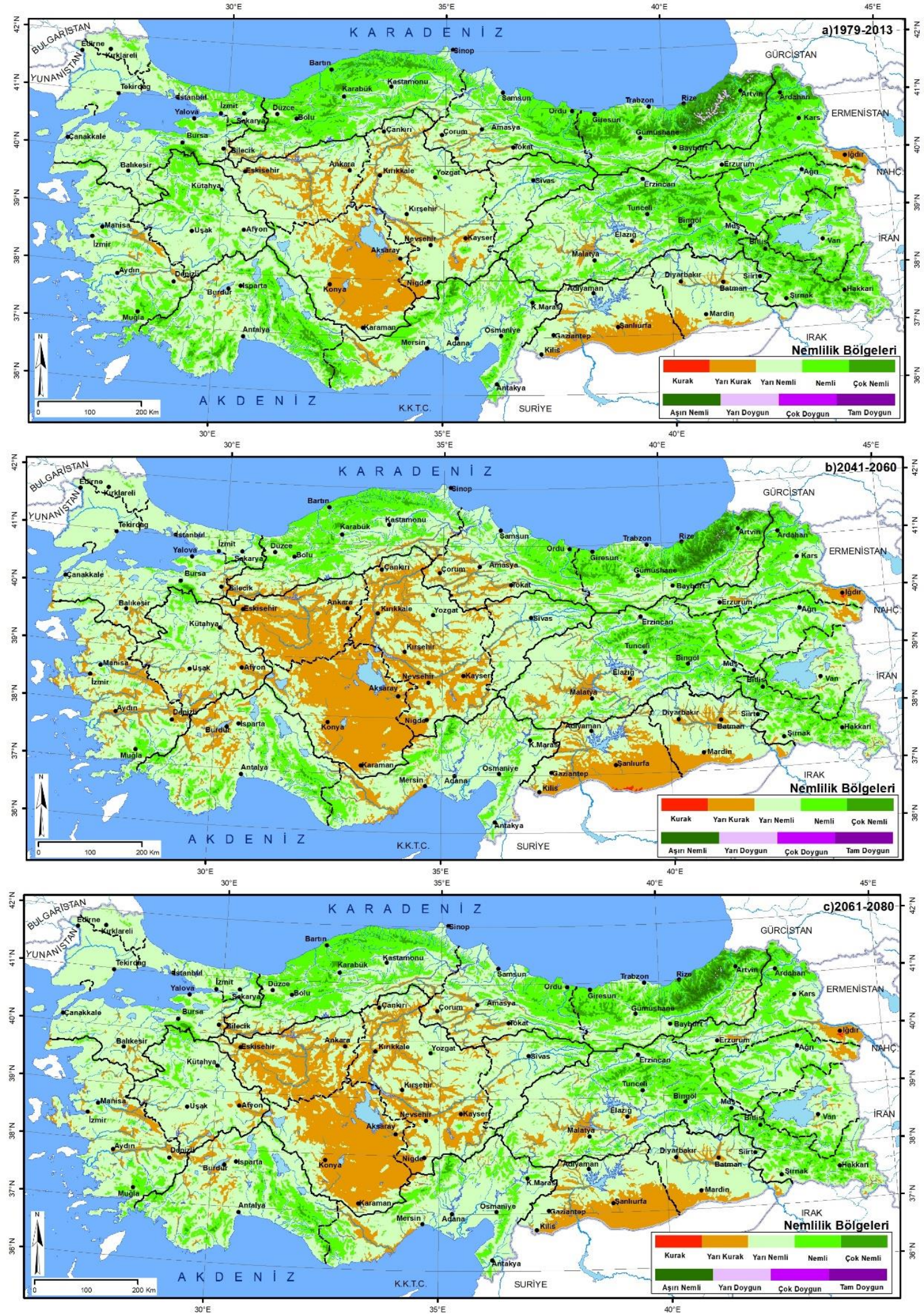

Şekil 5. HEB Sınıflandırmasına göre Türkiye'de Nemlilik Bölgeleri 
Yarı doygun ve çok doygun sahalar sadece Karadeniz ve Doğu Anadolu Bölgesinde yer almakta, toplam $743 \mathrm{~km}^{2}$ alan kaplamaktadır (Çizelge 2). Doğu Karadeniz Dağlarının zirveleri ve çevrelerinde ve Ağrı Dağı zirvesi etrafında karşımıza çıkan bu sahalardan yarı doygun alanlar, HadGEM2-CC iklim modeli verilerine göre daralmakta, çok doygun sahalar ise ortadan kalkmaktadır (Şekil 6). HEB sınıflandırmasına göre Türkiye'deki tam doygun sahalar, sadece Ağrı Dağı zirvesinde, 1 km² alan içerisinde belirlenmiştir ki bu saha günümüzde takke buzulu ile kaplıdır (Sarıkaya, 2011) (Çizelge 2, Şekil 5). İklim modeli verilerine göre 2041-2060 ve 2061-2080 dönemlerinde bu saha ortadan kalkmakta, yerini yarı doygun sahalar almaktadır (Şekil 6).

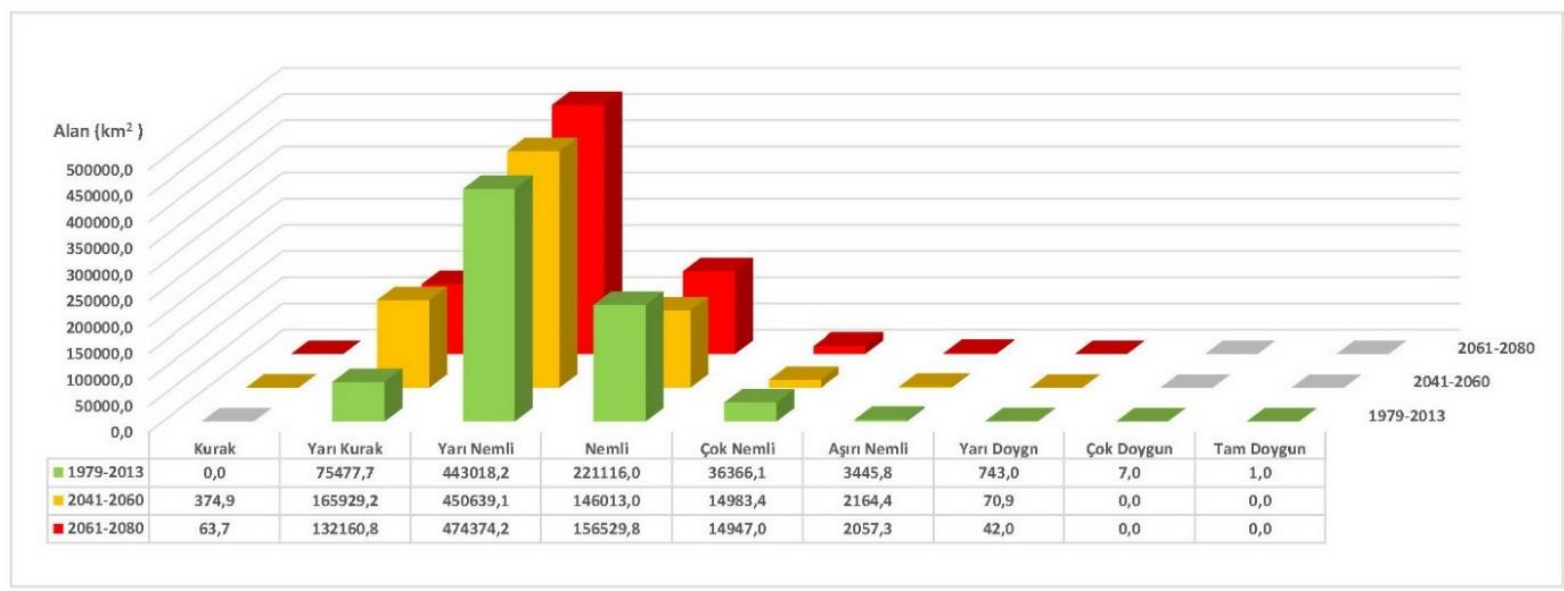

Şekil 6. Holdridge nemlilik bölgelerinin dönemlere göre alansal değişimi (Grafik ölçeği logaritmiktir).

HEB nemlilik sınıfları ile Türkiye için üretilen Thornthwaite yağış etkinlik indisi grupları (Yılmaz ve Çiçek, 2016) arasında büyük benzerlik bulunmaktadır. Örneğin, Thornthwaite yağış etkinliklerinden çok nemli-A sınıfındaki sahalar, HEB nemlilik sınıflarından çok nemli, yarı kurak-D sınıfı alanlar ise yarı kurak sahalar ile büyük benzerlik göstermektedir. Yine HEB sınıflarından doygun sahalar, Erinç ve Sezer iklim sınıflarından (Güngör, 2019; Sezer, 1988) çok nemli sahalarla, yarı kurak sahalar ise Sezer sınıflarından yarı kurak ve kurak-yarı nemli sahalar ile örtüşmektedir. Erinç ve De Martonne-Gottman bölgeleri ile HEB nemlilik sınıfları arasında tam bir ilişki yoksa da benzerlikler bulunmaktadir.

\subsection{HEB Sınıflamasına Göre Türkiye'nin Biyomları ve Değişimi}

Holdridge (1947) tarafindan yapılan HEB sınıflandırmasında, yıllık toplam yağış ve evapotranspirasyon oranına göre yapılan tasnifte benzer bitki sahası bölgeleri de tanımlanmıştır. $\mathrm{Bu}$ sınıflar ekolojik terminolojide biyomlara denk gelmektedir. Biyom, benzer çevre ve iklim şartlarında yaşayan bitki ve hayvan toplulukları ile yaşam birliklerini tarif etmek için kullanılmaktadır (Taylor, Myers ve Giller, 1989: 41; Türkeş, 2013: 5-6). Köppen sınıflandırması da temelde biyom sınırlarını ortaya koyma amacı gütmekte (Rohli, Vrga ve Rohli, 2018), Erinç sınıflandırması (Erinç, 1965) da genel anlamda bitki örtüsü bölgelerini ve dolayısıyla ortam bütünlüklerini ifade etmeyi amaçlamaktadır. HEB sınıflandırması biyomların belirlenmesi amacıyla da kullanılmış (Lugo vd., 1999), bu çalışmada da biyom teriminin kullanılması benimsenmiştir. 
Günümüzde Türkiye'de en kurak özellik gösteren biyom, çöl çalılığı alanlarıdır. Bu biyom Türkiye'de $700 \mathrm{~km}^{2}$ 'ye yaklaşan bir alana sahiptir (Çizelge 3). Doğubeyazıt ve Iğdır Ovası'nda karşımıza çıkan bu biyom (Şekil 8), HadGEM2-CC modeli verilerine göre 2041-2060 döneminde genişleyerek 1000 km² ye yaklaşmakta 2061-2080 döneminde daralmaktadır (Şekil 7). Iğdır ovası, özellikle Aralık çevresi, günümüzde rüzgar erozyonunun olduğu, çeşitli tedbirlerle erozyonun engellenmeye çalışıldığı bir sahadır (Karaoğlu, 2018). Günümüzde yetiştirilen kültür bitkileri, toprağı sabitleyerek kumul oluşumu engellemede önemli rol oynamaktadır. Buradaki ortam koşullarının gelecekte Doğubeyazıt Ovası'na da hâkim olabileceği görülmekte, bu sahaların stabilizasyonunun çölleşme açısından önemli bir rol oynayacağı anlaşılmaktadır.

Dikenli çalılık biyomu günümüzde Türkiye'nin \% 2'sine yakınını kaplamakta, bu sahaların büyük bir bölümü (\% 84,5'i) Güneydoğu Anadolu Bölgesinde yer almakta ve bölgenin \% 20 'ne yakınını oluşturmaktadır (Çizelge 3, Şekil 8). Dikenli çalılık biyomu, Güney Marmara ve Ege Bölgesinin kıyıdan uzak depresyonlarında, Diyarbakır ve Mut Havzalarında da görülmektedir. Bu sahalar, 2041-2060 döneminde genişlemekte, 2061-2080 döneminde daralsa da günümüzdekinin 2 katına yakın alan kaplamaktadır (Şekil 8, Şekil 7).

Dikenli step sahaları, Türkiye için ağaçlı step kavramına karşılık gelmekte, İç Anadolu Bölgesi bozkır sahalarını karakterize etmektedir. Dikenli stepler, Türkiye'nin \% 8,5'ini kaplamakta (Çizelge 3), baharda yeşeren, yaz başında sararan ve yaz sonuna doğru tohumlarını döken, tek ve birkaç yıllık bitkilerden oluşan sahaları ifade etmektedir. Türkiye'de en geniş yayıldı̆̆ saha İç Anadolu Bölgesinin batı yarısıdır. Ayrıca bölgeden kaynağını alan akarsu vadilerinde de bu biyoma rastlanmaktadır. Doğu Anadolu Bölgesinde Malatya, Erzurum, Iğdır gibi depresyon alanlarında, İç Ege Bölümü’nün plato ve ovalarında, Batı Torosların polyelerinde ve Orta Karadeniz Bölümü'nde de bu biyomun yayıldığ sahalar bulunur (Şekil 8). İklim modeli verilerine göre 2041-2060 döneminde bu sahalar genişlemekte, İç Anadolu Bölgesinin doğu yarısını da kaplamakta, buna rağmen 2061-2080 döneminde daralmaktadır (Şekil 7).

HEB sınıflandırmasına göre step sahaları, bildiğimiz anlamda İç Anadolu bozkırlarından çok, Doğu Anadolu Bölgesi yüksek bozkır sahaları ile karakterize edilebilir. Türkiye'nin \% 26,3'ünü kaplayan stepler, İç ve Doğu Anadolu Bölgesinin yüksek plato alanlarında, Uzunyayla Platosu çevresinde, Van Gölü doğusunda yayılış göstermekte, bir bakıma yüksek bozkırları yani sıcaklığın daha düşük olduğu yerlerdeki bozkırları, stepleri ifade etmektedir. İklim modeli verilerine göre bu sahalar 2041-2060 ve 2061-2080 dönemlerinde sürekli daralmakta, yerini dikenli step sahalarına bırakmaktadır (Şekil 8, Şekil 7).

Çizelge 3. HEB'e göre biyomların Türkiye coğrafi bölgelerindeki alanları ve oranları.

\begin{tabular}{crrrrrrrrr}
\hline Biyomlar & KB & \multicolumn{1}{c}{ MB } & EB & AB & IAB & DAB & GAB & \multicolumn{1}{c}{ Toplam } \\
\hline Çöl çalıı̆ı̆ı & 0,0 & 0,0 & 0,0 & 0,0 & 81,0 & 608,4 & 0,0 & 689,4 \\
\hline Türkiye Oranı (\%) & 0,00 & 0,00 & 0,00 & 0,00 & 11,75 & 88,25 & 0,00 & 100,00 \\
\hline Bölgesel Oran (\%) & 0,00 & 0,00 & 0,00 & 0,00 & 0,05 & 0,36 & 0,00 & 0,09 \\
\hline Dikenli çalılı & 0,0 & 0,0 & 1267,8 & 897,0 & 0,0 & 8,8 & 11817,6 & 13991,2 \\
\hline Türkiye Oranı (\%) & 0,00 & 0,00 & 9,06 & 6,41 & 0,00 & 0,06 & 84,46 & 100,00 \\
\hline Bölgesel Oran (\%) & 0,00 & 0,00 & 1,54 & 0,81 & 0,00 & 0,01 & 19,22 & 1,79 \\
\hline Dikenli Step & 4431,4 & 570,1 & 1053,2 & 2820,7 & 45695,5 & 5663,9 & 5859,1 & 66093,8 \\
\hline
\end{tabular}


Erkan Yllmaz

\begin{tabular}{|c|c|c|c|c|c|c|c|c|}
\hline Türkiye Oranı (\%) & 6,70 & 0,86 & 1,59 & 4,27 & 69,14 & 8,57 & 8,86 & 100,00 \\
\hline Bölgesel Oran (\%) & 3,30 & 0,91 & 1,28 & 2,55 & 28,44 & 3,35 & 9,53 & 8,47 \\
\hline Step & 32129,0 & 403,9 & 10562,1 & 10031,5 & 101480,3 & 50190,3 & 153,2 & 204950,3 \\
\hline Türkiye Oranı (\%) & 15,68 & 0,20 & 5,15 & 4,89 & 49,51 & 24,49 & 0,07 & 100,00 \\
\hline Bölgesel Oran (\%) & 23,96 & 0,65 & 12,87 & 9,08 & 63,17 & 29,72 & 0,25 & 26,27 \\
\hline Kurak orman & 12116,8 & 52743 , & 50936,3 & 55346,0 & 723,8 & 18061,2 & 41850,9 & 231778,3 \\
\hline Türkiye Oranı (\%) & 5,23 & 22,76 & 21,98 & 23,88 & 0,31 & 7,79 & 18,06 & 100,00 \\
\hline Bölgesel Oran (\%) & 9,03 & 84,46 & 62,06 & 50,08 & 0,45 & 10,70 & 68,05 & 29,71 \\
\hline Nemli orman & 63899,1 & 8351,2 & 17838,9 & 36829,5 & 12073,3 & 73815,6 & 1786,3 & 214593,9 \\
\hline Türkiye Oranı (\%) & 29,78 & 3,89 & 8,31 & 17,16 & 5,63 & 34,40 & 0,83 & 100,00 \\
\hline Bölgesel Oran (\%) & 47,64 & 13,37 & 21,73 & 33,32 & 7,51 & 43,71 & 2,90 & 27,51 \\
\hline Nemli orman (Dağlık) & 1457,3 & 0,0 & 0,0 & 354,5 & 395,2 & 4746,1 & 0,0 & 6953,1 \\
\hline Türkiye Oranı (\%) & 20,96 & 0,00 & 0,00 & 5,10 & 5,68 & 68,26 & 0,00 & 100,00 \\
\hline Bölgesel Oran (\%) & 1,09 & 0,00 & 0,00 & 0,32 & 0,25 & 2,81 & 0,00 & 0,89 \\
\hline Ilskak orman & 8434,4 & 299,6 & 384,5 & 2989,2 & 0,0 & 4635,0 & 30,2 & 16772,9 \\
\hline Türkiye Oranı (\%) & 50,29 & 1,79 & 2,29 & 17,82 & 0,00 & 27,63 & 0,18 & 100,00 \\
\hline Bölgesel Oran (\%) & 6,29 & 0,48 & 0,47 & 2,70 & 0,00 & 2,74 & 0,05 & 2,15 \\
\hline Islak orman (Dağlık) & 7670,5 & 22,2 & 26,6 & 1211,5 & 198,5 & 10937,1 & 0,0 & 20066,3 \\
\hline Türkiye Oranı (\%) & 38,23 & 0,11 & 0,13 & 6,04 & 0,99 & 54,50 & 0,00 & 100,00 \\
\hline Bölgesel Oran (\%) & 5,72 & 0,04 & 0,03 & 1,10 & 0,12 & 6,48 & 0,00 & 2,57 \\
\hline Yağmur ormanı & 487,2 & 0,0 & 0,0 & 0,0 & 0,0 & 0,0 & 0,0 & 487,2 \\
\hline Türkiye Oranı (\%) & 100,00 & 0,00 & 0,00 & 0,00 & 0,00 & 0,00 & 0,00 & 100,00 \\
\hline Bölgesel Oran (\%) & 0,36 & 0,00 & 0,00 & 0,00 & 0,00 & 0,00 & 0,00 & 0,06 \\
\hline Yağmur ormanı (Dağlık) & 2810,5 & 61,1 & 5,9 & 10,0 & 0,0 & 77,4 & 0,0 & 2964,9 \\
\hline Türkiye Oranı (\%) & 94,79 & 2,06 & 0,20 & 0,34 & 0,00 & 2,61 & 0,00 & 100,00 \\
\hline Bölgesel Oran (\%) & 2,10 & 0,10 & 0,01 & 0,01 & 0,00 & 0,05 & 0,00 & 0,38 \\
\hline Islak tundra & 0,0 & 0,0 & 0,0 & 0,0 & 10,0 & 53,0 & 0,0 & 63,0 \\
\hline Türkiye Oranı (\%) & 0,00 & 0,00 & 0,00 & 0,00 & 15,87 & 84,13 & 0,00 & 100,00 \\
\hline Bölgesel Oran (\%) & 0,00 & 0,00 & 0,00 & 0,00 & 0,01 & 0,03 & 0,00 & 0,01 \\
\hline Yağmurlu tundra & 679,5 & 0,0 & 0,0 & 28,0 & 0,0 & 38,9 & 0,0 & 746,5 \\
\hline Türkiye Oranı (\%) & 91,03 & 0,00 & 0,00 & 3,75 & 0,00 & 5,21 & 0,00 & 100,00 \\
\hline Bölgesel Oran (\%) & 0,51 & 0,00 & 0,00 & 0,03 & 0,00 & 0,02 & 0,00 & 0,10 \\
\hline Soğuk çöl & 3,0 & 0,0 & 0,0 & 0,0 & 0,0 & 12,0 & 0,0 & 15,0 \\
\hline Türkiye Oranı (\%) & 19,99 & 0,00 & 0,00 & 0,00 & 0,00 & 80,01 & 0,00 & 100,00 \\
\hline Bölgesel Oran (\%) & 0,00 & 0,00 & 0,00 & 0,00 & 0,00 & 0,01 & 0,00 & 0,00 \\
\hline Buz (Buzul) & 0,0 & 0,0 & 0,0 & 0,0 & 0,0 & 9,0 & 0,0 & 9,0 \\
\hline Türkiye Oranı (\%) & 0,00 & 0,00 & 0,00 & 0,00 & 0,00 & 100,00 & 0,00 & 100,00 \\
\hline Bölgesel Oran (\%) & 0,00 & 0,00 & 0,00 & 0,00 & 0,00 & 0,01 & 0,00 & 0,00 \\
\hline Toplam & 134118 & 62451, & 82075,3 & 110517,8 & 160657,6 & 168856,7 & 61497,4 & 780174,8 \\
\hline Türkiye Oranı (\%) & 17,19 & 8,00 & 10,52 & 14,17 & 20,59 & 21,64 & 7,88 & 100,00 \\
\hline
\end{tabular}

Çok kuru orman alanları günümüzde Türkiye'de bulunmazken (Şekil 8), 2041-2060 döneminde Silifke Deltası ve çevresindeki kıyılarda görülmeye başlamakta, 2061-2080 döneminde daha da genişlemekte, $200 \mathrm{~km}^{2}$ 'yi geçmektedir (Şekil 7).

HEB sınıflandırmasında kurak orman olarak gösterilen sahalar, Türkiye için kızılçam alanlarını (OGM, 2012) karakterize edilebilse de günümüzde Trakya ve Güneydoğu Anadolu Bölgesinin alçak sahalarında kızılçamlara rastlanmaması, bu sahaların bu biyom için uygun ortam koşullarına sahip olduğunu, fakat başka amaçlarla kullanıldığını göstermektedir (Şekil 8). Kurak orman alanları Türkiye'nin \% 30'una yakınını kaplamakta, tüm bölgelerimizde dağılış göstermektedir. Model verilerine göre bu biyom 2041-2060 ve 2061-2080 dönemlerinde sürekli genişlemekte, günümüzde 231 bin $\mathrm{km}^{2}$ iken, yaklaşık bir buçuk kat artmakta ve 346 bin km² alan kaplamaktadır (Şekil 7). 


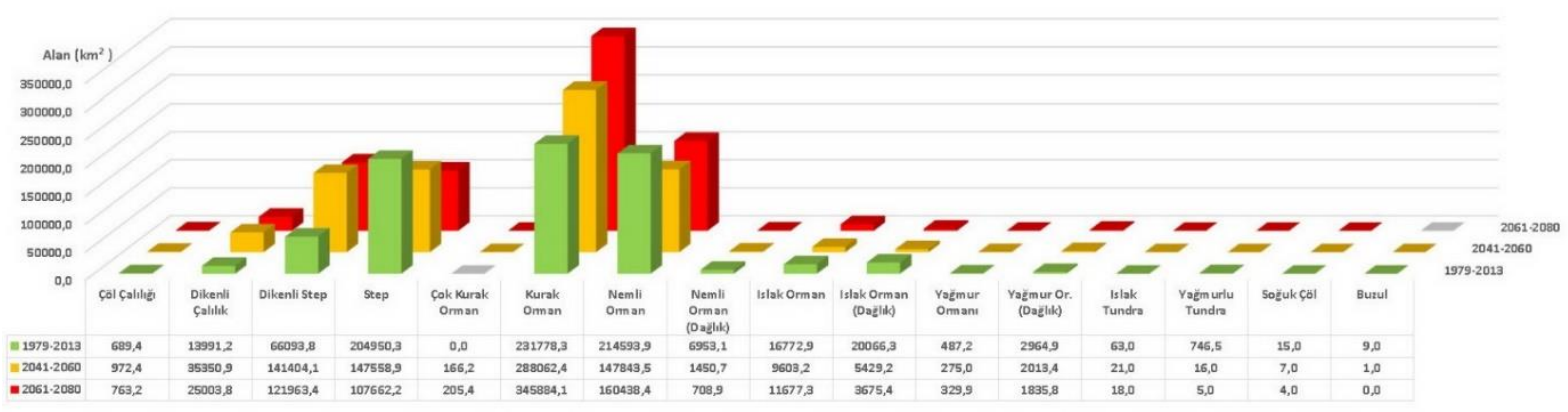

Şekil 7. HEB sınıflandırmasına göre Türkiye'de biyomların alansal değişimi.

HEB sinıflandırmasına göre Türkiye'nin \% 27,5'ini kaplayan nemli orman biyomu, Türkiye'deki orman alanlarının (OGM, 2012) büyük bölümünü kaplamaktadır. Bu biyom hem Karadeniz Bölgesinde fazla nem isteyen ormanları, hem AB'de Toroslar üzerinde yer alan yaz kuraklığına dayanıklı orman alanları hem de Doğu Anadolu Bölgesindeki meşe ormanları yer almaktadır. Bu açıdan Türkiye içerisindeki farklı karakterdeki orman alanlarını bu biyomda tek sınıf olarak görülmektedir. Nemli orman biyomu, 1979-2013 ortalamalarına göre 215 bin $\mathrm{km}^{2}$ alan kaplamakta, iklim modeli verilerine göre 2041-2060 döneminde daralarak 148 bin km², 2061-2080 döneminde (160 bin $\mathrm{km}^{2}$ ) biraz genişlese de günümüze göre daha dar bir alanda belirlenmiştir (Şekil 7). Daha serin sahalarda görülen dağlık nemli ormanlar biyomu da daralmakta, 2041-2060 döneminde 1000 $\mathrm{km}^{2}$ 'nin altına inmektedir.

Islak ormanlar yağışın, nemli ormana göre yüksek, yağmur ormanına göre daha düşük olduğu biyomdur ve günümüzde Güneydoğu Toroslar, Teke ve Taşeli Platoları, Köroğlu, Küre ve Doğu Karadeniz Dağları'nın yüksek kesimleri ile Uludağ çevresinde belirlenmiştir. Islak ormanlar, yükseklerde görülen dağlık sslak orman biyomu ile birlikte Türkiye'de 37 bin $\mathrm{km}^{2}$ alan kaplamakta, daha çok Karadeniz ve Doğu Anadolu Bölgesinde karşımıza çıkmaktadır. Dağlık 1slak orman biyomu, Doğu Karadeniz Dağları, Uludağ, Bolkar Dağları, Aladağlar (Niğde), Munzur Dağları, Bingöl, Süphan, Tendürek, Mengene, İhtiyarşahap gibi dağlık alanlarda görülmekte (Şekil 8), sayılan sahalar genel olarak Würm buzullaşmasının görüldüğü günümüz periglasyal sahaları özelliği göstermektedir. Islak orman biyomları HadGEM2-CC iklim modeli verilerine göre sürekli daralmakta, alanı 2061-2080 döneminde 15 bin $\mathrm{km}^{2}$ 'nin altına inmektedir (Şekil 7).

Yağmur ve dağlık yağmur ormanı biyomları, tropikal bölgelerde, sürekli yağış alan ormanları ifade eden bir terim olsa da HEB sınıflandırmasına göre Türkiye'de görülmekte ve daha çok serin karakterli, dağlık özellik göstermektedir. Bu biyomların \% 95'inden fazlası Doğu Karadeniz Bölümü’nün yüksek kesimlerinde karşımıza çıkmakta (Şekil 8), bu sahadaki eski buzul alanları, günümüz periglasyal alanları, alpin çayırların görüldüğü sahaları kapsamaktadır. Yağmur orman biyomları, 1979-2013 ortalamalarına göre $3500 \mathrm{~km}^{2}$ alana yaklaşmakta (Çizelge 3), iklim modeli verilerine göre (özellikle dağlık karakterli) sürekli daralma göstermektedir. 

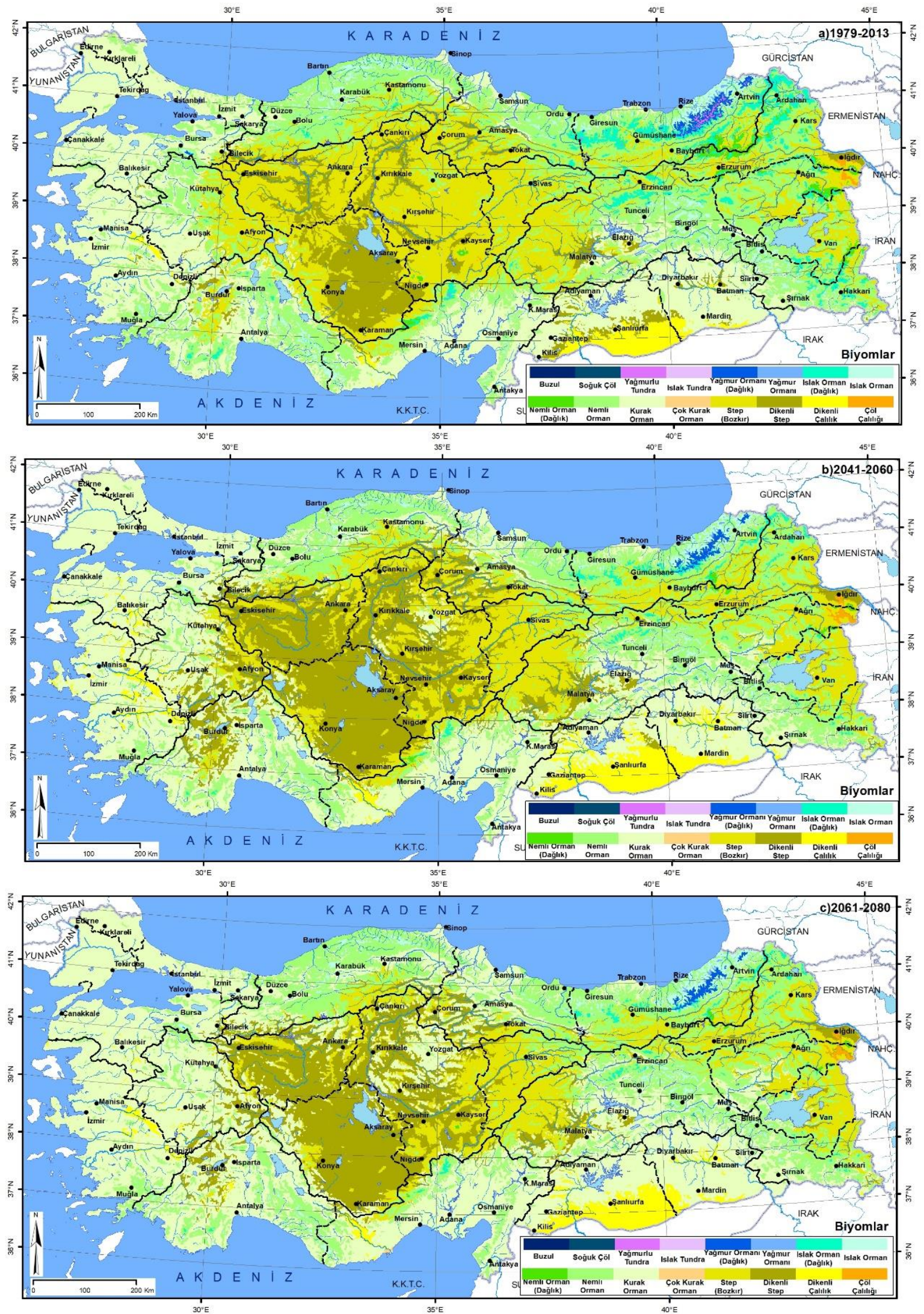

Şekil 8. HEB sınıflandırmasına göre Türkiye'de biyomlar. 
HEB tanımlamasına göre belirlenen tundra alanları Türkiye'de, Karadeniz Bölgesinin yüksek kesimleri ile Aladağlar (Niğde), Keşiş Dağları'nda ve Ağrı, Süphan, Erciyes volkanik dağlarının zirve çevrelerinde görülmektedir. Tundra alanları günümüz ortalamalarına göre Türkiye'de $800 \mathrm{~km}^{2}$ civarında alan kaplamakta ve \% 90'1ndan fazlası Karadeniz Bölgesi'nde yer almaktadır (Çizelge 3). Bu biyom, HadGEM2-CC iklim modeli verilerine daralmakta, 2061-2080 döneminde $20 \mathrm{~km}^{2}$ yi ancak geçmektedir.

Günümüz ortalamalarına göre $15 \mathrm{~km}^{2}$ alana sahip olan soğuk çöl sahalarının \% 80'dan fazlası Ağrı Dağı çevresinde geriye kalan kısmı ise Doğu Karadeniz Dağları'nın çok yüksek kısımlarında karşımıza çıkmaktadır (Şekil 8). Bu sahalar, iklim modeli verilerine göre daralmakta, 2061-2080 döneminde $4 \mathrm{~km}^{2}$ alan kaplamaktadır (Şekil 7). HEB biyomları içerisinde buzul (buz-donmuş) sahaları da bulunmakta, günümüzde $9 \mathrm{~km}^{2}$ alan kaplamakta, bu sahaların tamamı Doğu Anadolu Bölgesi'nde Ağrı Dağı zirvesi çevresinde yer almaktadır. İklim modeli verilerine göre bu sahalar da 2041-2060 döneminde ancak $1 \mathrm{~km}^{2}$ alan kaplarken 2061-2080 döneminde ortadan kalkmakta (Şekil 8, Şekil 7), bir kısmı soğuk çöllere dönüşmektedir. Leemans (1990) tarafindan yapılan çalışmada, Grönland çevresi soğuk çöl olarak belirlenmiş, bu biyomun esasında buzul sahası olduğu görülmüştür. Türkiye için buzul sahaları belirlenirken hem buzul hem de soğuk çöl sahaları birlikte değerlendirilmelidir.

Türkiye'nin potansiyel bir bitki örtüsü belirleme çalışmasına göre (Raja vd., 2019) Türkiye'de geniş ve iğne yapraklı orman alanları ile çalılık ve karışık saha ortamlarının bulunduğu görülmüştür. Bunlardan çalılık alanları, HEB sınıflarından dikenli steplerle, iğne yapraklı ormanlar ile de kurak orman sahası benzerlik göstermektedir.

\subsection{Türkiye'nin Tümleşik Holdridge Ekolojik Bölgeleri ve Değiş̧imi}

Çalışma sonucunda, HEB'e göre oluşturulan yükselti-ekolojik katları, nemlilik sınıfları ve biyomlar birleştirilerek tümleşik bir Holdridge ekolojik bölge sınıflandırması yapılmış, Türkiye'de günümüzde 63 sınıf olduğu görülmüştür. Bu sınıflar içerisinde en geniş alanı, dağlık-yarı nemli-step (40706-kod bilgileri için Not 1'e bakınız), en dar alanı ise karlı-çok doygun-buzul (70220) alanları kaplamaktadır (Şekil 9). Analizler sonucunda, 1979-2013 ortalamaları ile 2041-2060 ve 2061-2080 dönemlerindeki HEB sınıfları incelenmiş ve bazı sınıfların sürekli daralırken, bazılarının genişlediği, bazılarının ortadan kalkarken bazı bölgelerde yeni sınıfların da oluştuğu görülmüştür (Şekil 10).

Model verilerine göre, günümüzde Türkiye'de bulunan tümleşik HEB sınıflarından dağlık-yarı nemli-çöl çalılıkları (40702), yarıalpin-aşırı nemli-yağmurlu tundralar (50418), alpin-çok doygunyağmurlu tundralar (60218), yarı doygun-dağlık yağmur ormanları (60314), çok nemli-dağlık sslak orman (60512), çok nemli-yağmurlu tundra (60518), nemli-dağlik nemli orman (60610), karl1-tamdoygun-buzul (70120), çok doygun-soğuk çöl (70219) ve çok doygun-buzul (70220) alanları 2041-2060 ve 2061-2080 dönemlerinde ortadan kalkmaktadır. 2041-2060 döneminde ortaya çıkan alpin-aşırı nemli-soğuk çöl (60419) alanları 2061-2080 döneminde ortadan kalkmış, 2041-2060 döneminde ortadan kalkan alpin-aşırı nemli-1slak tundra (60417) alanları ise 2061-2080 döneminde tekrar görülmüş, alçak irtifa-nemli-1slak orman (20611) alanları ise 2061-2080 döneminde ortaya çıkmıştır (Şekil 9, Şekil $10)$. 
Günümüze göre alanı sürekli genişleyen 8 sınıf bulunmakta, bunlar alçak irtifa-yarı nemli-kurak orman (20708), yarı kurak-kurak orman (20808), dağönü-yarı nemli-dikenli step (30705), yarı nemlikurak orman (30708), yarı kurak-çöl çalılığı (30802), dağlık-aşırı nemli-1slak orman (40411), dağlık yağmur ormanı (40414), yarı nemli-kurak orman (40708) alanları olarak sıralanmaktadır.

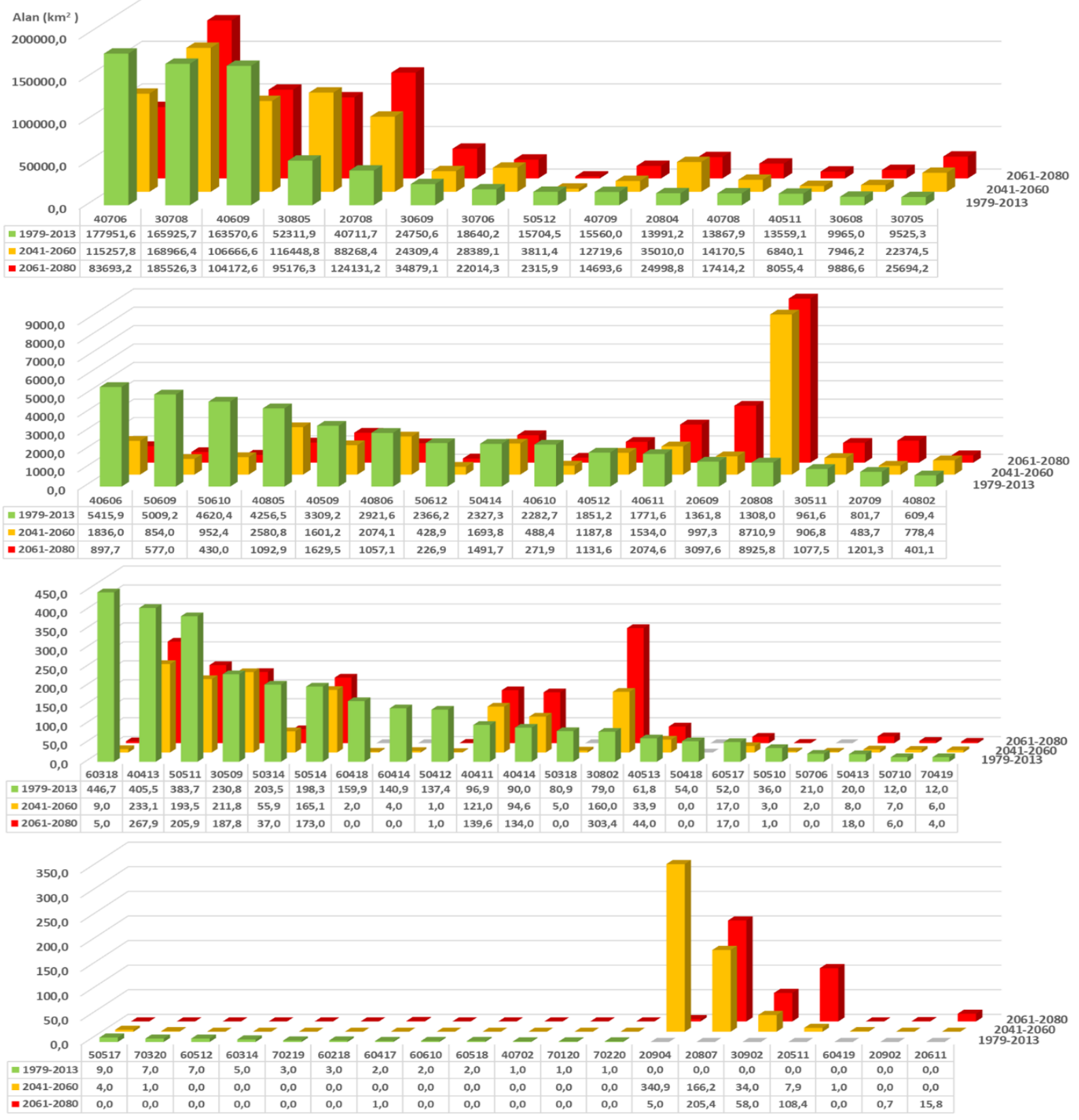

Şekil 9. Tümleşik HEB sınıflarının alanları ve zamansal değişimi.

2041-2060 döneminde alanı genişlerken 2061-2080 döneminde daralan 4 tümleşik HEB bölgesi bulunmaktadır. Bunlar içerisinde alçak irtifa-yarı kurak-dikenli çalılıklar (20804), dağönü-yarı nemlistepler (30706), yarı kurak-dikenli stepler (30805) ve dağlık-yarı kurak-çöl çalılıkları (40802) bulunmaktadır (Şekil 9). 


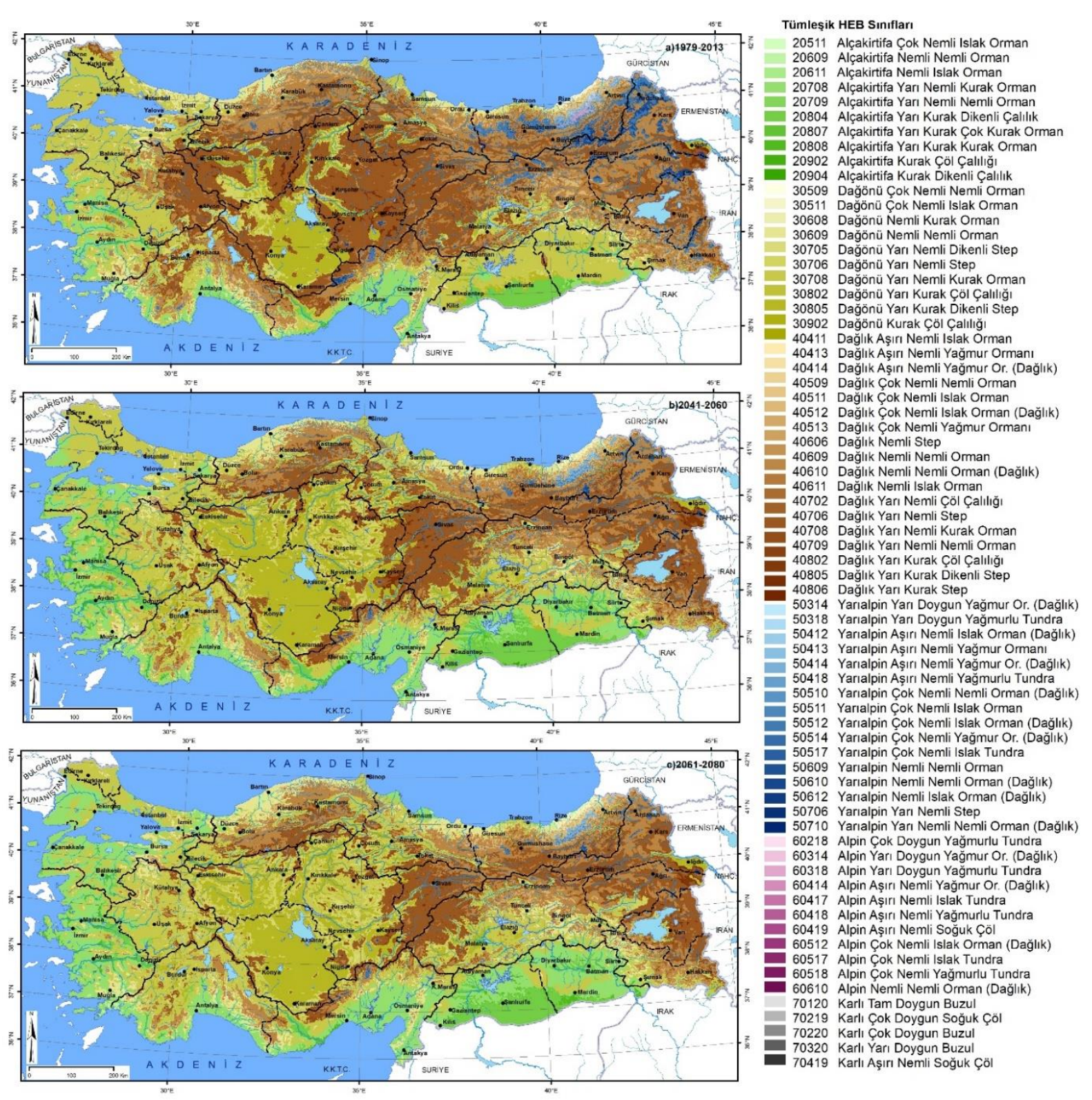

Şekil 10. Türkiye'de tümleşik HEB sınıfları.

Belirlenen dönemlerde alanı sürekli azalan sahalar içerisinde, dağönü-çok nemli-nemli ormanlar (30509) ve dağl1k islak ormanlar (40512), nemli-stepler (40606), nemli ormanlar (40609), dağlık nemli ormanlar (40610), yar1 nemli-stepler (40706), yarı kurak-dikenli stepler (40805) ve stepler (40806), yarıalpin-yarı doygun-dağlık yağmur ormanları (50314) ve yağmurlu tundralar (50318), aşırı nemlidağlık yağmur ormanları (50414), çok nemli-dağlık nemli ormanlar (50510), dağlık sslak ormanlar (50512) ve sslak tundralar (50517), nemli-nemli ormanlar (50609), dağlık nemli ormanlar (50610) ve dağlık ıslak ormanlar (50612), yarı nemli-stepler (50706) ve dağlık nemli ormanlar (50710), alpin-yarı doygun-yağmurlu tundralar (60318), aşırı nemli-dağlık yağmur ormanları (60414) ve yağmurlu tundralar (60418), çok nemli-1slak tundralar (60517), yarı doygun-buzul alanları (70320) ve karlı-aşırı nemli-soğuk çöller (70419) bulunmaktadır (Şekil 9). 
2041-2060 döneminde alanı daralırken 2061-2080 döneminde genişleyen sahalar da bulunmaktadır Bu sınıflar içerisinde alçak irtifa-nemli-nemli ormanlar (20609), yarı nemli-nemli ormanlar (20709), dağönü-çok nemli-1slak ormanlar (30511), nemli-kurak ormanlar (30608) ve nemli ormanlar (30609), dağlık-aşırı nemli-yağmur ormanları (40413), çok nemli-nemli ormanlar (40509), ıslak ormanlar (40511) ve yağmur ormanları (40513), nemli-1slak ormanlar (40611), yarı nemli-nemli ormanlar (40709), yarıalpin-aşırı nemli-dağlık ıslak ormanlar (50412), yağmur ormanları (50413), çok nemli-1slak ormanlar (50511), dağlık yağmur ormanları (50514) yer almaktadır.

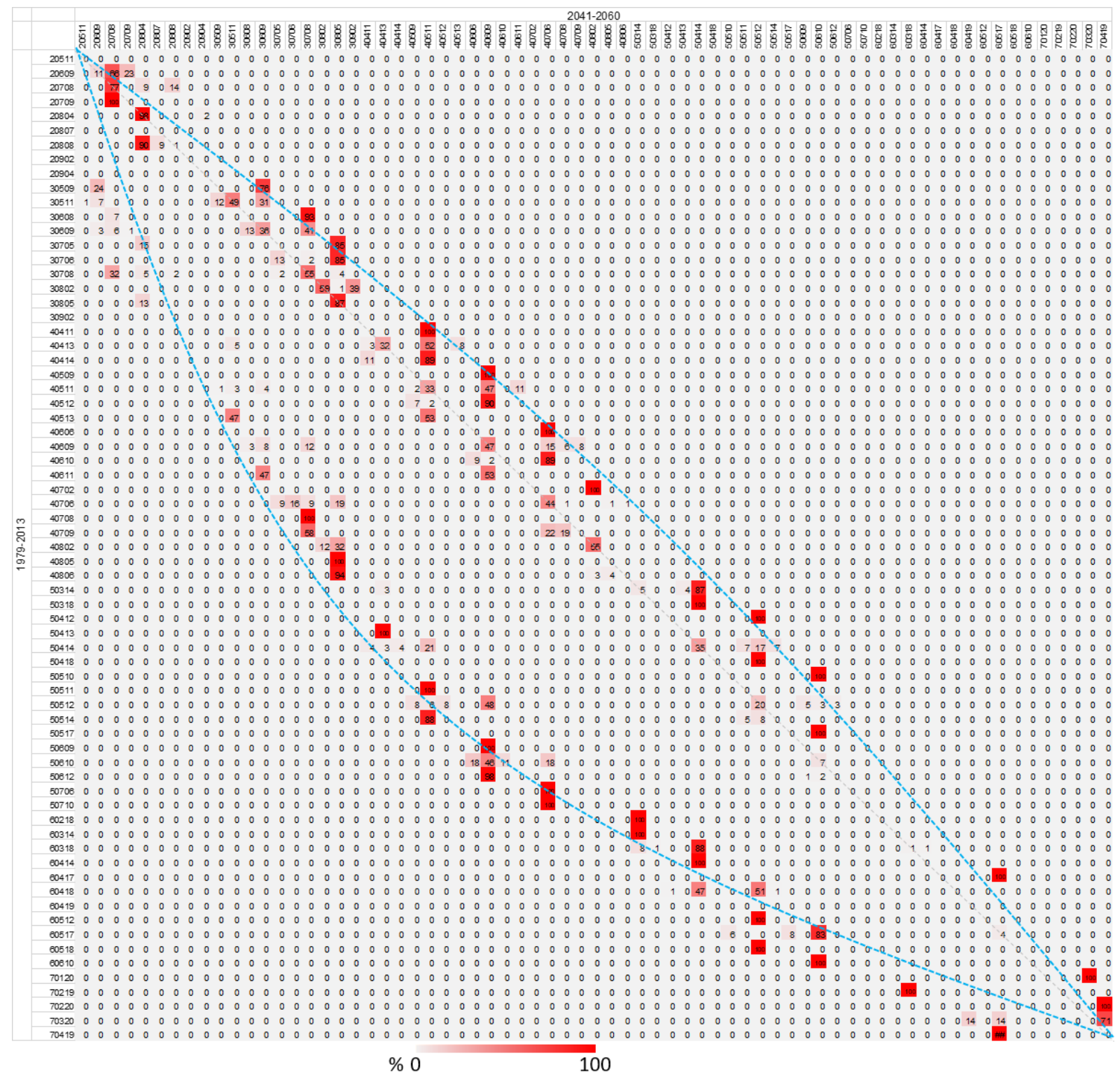

Şekil 11. Tümleşik HEB sınıflarının ${ }^{1}$ 1979-2013 ve 2041-2060 dönemleri arasında değişim matrisi (Oranlar, 1979-2013 yılı alanlarına göre verilmiştir).

Günümüzde Türkiye şartlarında görülmeyen ekolojik bölgelerden, alçak irtifa-çok nemli-1slak orman (20511), yarı kurak-çok kurak orman (20807), kurak-çöl çalılığı (20902) ile dikenli çalılık (20904) ve dağönü-kurak-çöl çalıllı̆ı (30902) alanları, hem 2041-2060 hem de 2061-2080 dönemlerinde belirlenmiştir (Şekil 9). 
Günümüz ve 2041-2060 dönemi HEB sınıfları için bir değişim matrisi oluşturularak karşılaştırma yapılmış (Şekil 11), sınıfların bir kısmının düşük bir oranının matris köşegeni üzerinde kaldığı, yer değiştirmediği, genel olarak ise, tüm sınıfların yer değiştirdiği (göç ettiği) belirlenmiştir. Matristeki değişim, köşegenin sadece bir yönüne doğru oluşmamış, her iki yöne de yer değiştirme görülmüştür. Bu değişim simetrik olmamış, asimetrik bir elips meydana gelmiştir. Değişim matrisinde, elde edilen kodların özelliğine göre, sağa ve aşağı doğru hareket, yağış artışını ve PEO değerinin azalmasını göstermektedir. Buna bağlı olarak, sınıfların sadece sıcaklık artışına bağlı bir değişimi değil, nemlilik değerlerini de yansıtacak şekilde yer değiştirdiği, göç ederken başka bazı sınıfların yerini aldığı, kendi yerini ise başka sınıflara bıraktığı anlaşılmaktadır.

Genel bir değerlendirme yapıldığında, HEB sınıflamasına göre 1979-2013 ortam koşullarının, 2041-2060 ve 2061-2080 dönemlerinde Akdeniz ve Ege kıyılarında sürekli genişlerken, İç ve Doğu Anadolu Bölgesindeki plato ve yüksek dağlık alan ortamları sürekli azalmaktadır (Şekil 12). İç Anadolu Bölgesinin alçak kesimlerinde, Güneydoğu Anadolu Bölgesi güneyi ve Doğu Anadolu Bölgesinin alçak, depresyon alanlarındaki yarı kurak step sahaları ise 2041-2060 döneminde genişlerken, 2061-2080 döneminde daralmaktadır. Sürekli azalan ve sürekli artan sahalar arasında kalan, dağlık-plato alanlarında hâkim olan ortam koşulları 2041-2060 döneminde daralmakta, 2061-2080 döneminde ise genişlemektedir.

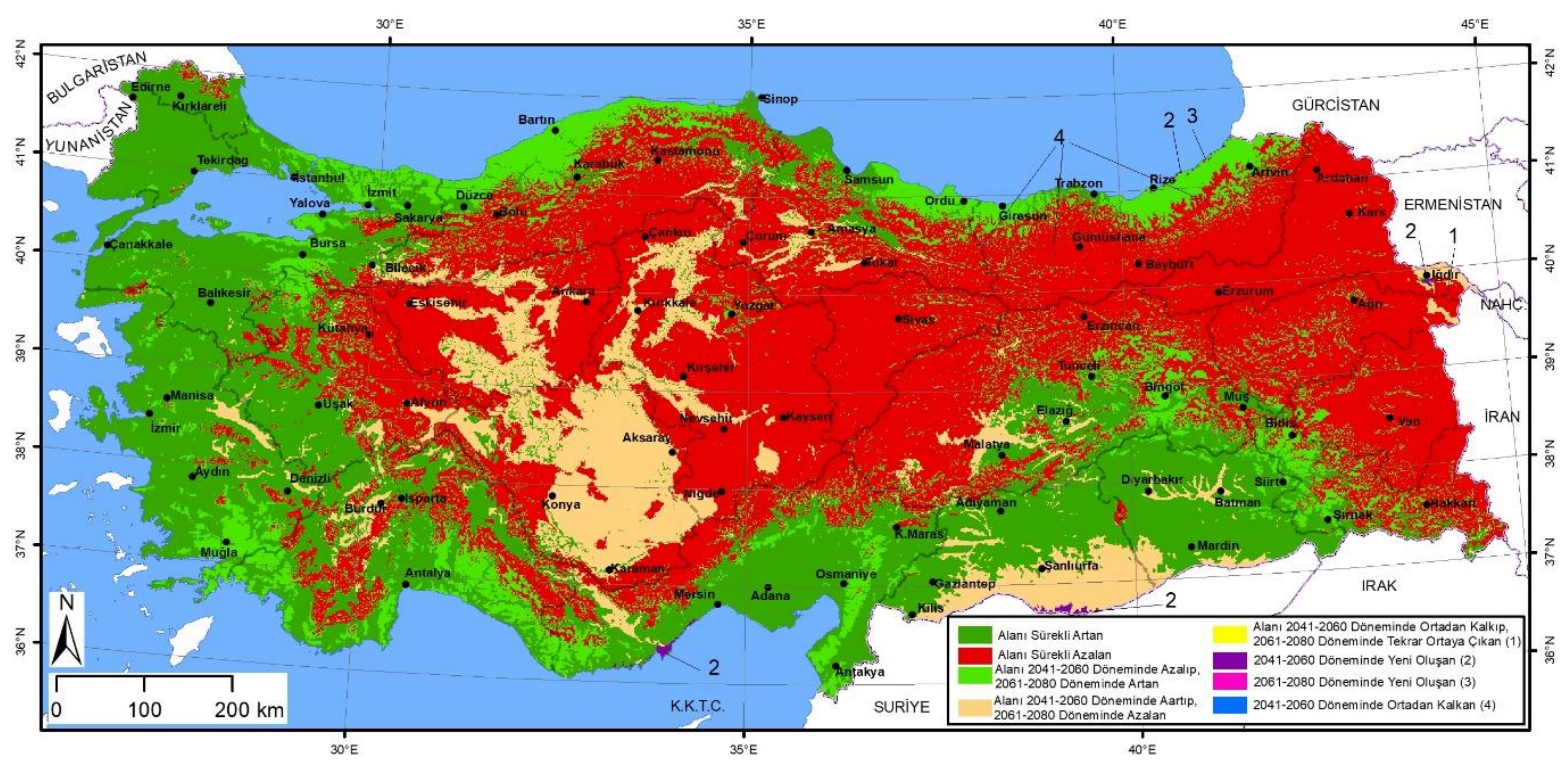

Şekil 12. HEB sınıflarında meydana gelebilecek değişimin genelleştirilmiş hali (Harita ölçeği nedeniyle görülemeyen sahalar rakamlarla verilmiş, harita işaretlerinde belirtilmiştir).

Türkiye'nin yüksek dağlarının zirvelerindeki ortam koşulları 2041-2060 döneminde ortadan kalkmakta, bu dağların zirve çevrelerindeki ortamların ortadan kalkması ise 2061-2080 dönemine denk gelmektedir (Şekil 12). Bununla beraber, 2041-2060 döneminde, Silifke Ovası çevresinde, Güneydoğu Anadolu Bölgesi güneyinde ve Iğdır Ovası'nda yeni kurak sahalar oluşmaya başlamaktadır. 


\section{Sonuç}

Türkiye için HEB bölgeleri ile ilgili çalışmalar daha evvel yapılımış (Tatli ve Dalfes, 2016; Tatl1, 2017; Tekin vd., 2018), bu çalışmalar istasyon temelli yapılmış, Leemans (1990) tarafından yapılan çalışma ise yeterli çözünürlügü sağlamamıştır. Bu çalışmada, Karger vd. (2017) tarafından 1979-2013 döneminde ait ERA-Interim ve 2041-2060 ve 2061-2080 dönemlerine ait HADGEM2-CC modelinin çözünürlüğü artırılmış (1 km) verileri kullanılarak Türkiye'ye ait güncel ve gelecekteki muhtemel HEB sınıflandırması yapılmış, ekolojik bölge sınırları belirlenmiştir. Çalışmada ayrıca coğrafi bilgi sistemleri yazılımları ile mekânsal eşleşme (geocoding-spatial join) tekniği kullanılarak, daha hızlı ve güvenli bir HEB tanımlaması yapılabileceği ortaya koyulmuş, diğer iklim sınıflandırmalarında da kullanılabilecek bir teknik geliştirilmiştir. Çalışmada yapılan analizler neticesinde aşağıdaki sonuçlara ulaşılmıştır.

1- Türkiye'de günümüzde hâkim olan HEB yükselti ekolojik bölgelerinden alçak irtifa ve dağönü kuşakları, HADGEM2-CC iklim modeli sonuçlarına göre 2041-2060 ve 2061-2080 dönemlerinde sıcaklık artışına bağlı olarak sürekli genişlerken, dağlık ortamlar daralmakta, günümüz alanının yarısına kadar inmektedir. Günümüzde çok dar alan kaplayan yarıalpin, alpin, karlı katlar ise daha daralarak çok sınırlı sahalarda varlığını sürdürmekte, karlı alanlar neredeyse ortadan kalkmaktadır.

2- HEB sınıflandırmasına göre günümüz ortalamalarına göre kurak saha bulunmazken, 2041 2060 döneminde ortaya çıkmaktadır. Türkiye'nin onda birini kapayan yarı kurak sahalar ise 2041-2060 döneminde genişlerken, 2061-2080 döneminde yağışı artan bölgelerde daralmaktadır. Türkiye'de en geniş alana sahip yarı nemli sahaları ise sürekli genişlemektedir. Nemli sahalar, yarı kurak sahalara benzer şekilde önce daralmakta sonra genişlemektedir. Çok ve aşırı nemli ile yarı doygun sahalar sürekli daralırken, çok ve tam doygun sahalar 2041-2060 döneminde sonra ortadan kalkmaktadır.

3- Türkiye'de HEB sınıflandırmasına göre günümüzde çöl çalılı̆̆g, dikenli çalılık, dikenli step, kura, nemli, ıslak ve yağmur ormanları, ıslak ve yağmurlu tundralar ile soğuk çöl ve buzul biyomları bulunmaktadır. Çöl çalılıkları, dikenli çalılıklar ve dikenli stepler 2041-2060 döneminde genişleyip, 2061-2080 döneminde daralırken, step sahaları sürekli daralmakta, kurak ormanlar sürekli genişlemekte, 2041-2060 döneminden sonra çok kurak orman sahaları da ortaya çıkmaktadır. Nemli ve sslak ormanlar ile yağmur ormanları 2041-2060 döneminde daralıp, 2061-2080 döneminde genişlemekte, dağlık nemli, ıslak ve yağmur ormanları sürekli daralmaktadır. Türkiye'deki tundra alanları ile soğuk çöller sürekli daralırken, buzul sahaları 2061-2080 döneminde ortadan kalkmaktadır.

4-Genel olarak, Türkiye'nin güneyinde ve kıyılarında yer alan, sıcak ortam koşulları genişlemekte, buna rağmen, yüksek dağlık alanlarda yer alan soğuk-serin ortamlar daralmakta, çok yüksekte bulunan soğuk çöller ve buzul ortamları ortadan kalkmaktadır. Türkiye'nin güneydoğu sınırında ve Doğu Akdeniz kıyılarında sıcak-kurak, Doğu Karadeniz kıyılarında ise sıcak-nemli ortamlar oluşmaya başlamaktadır. Türkiye'de günümüzde bulanan tüm ortamlar yer değiştirmekte-göç etmektedir. Bu değişiklik, tüm canlı ortamlarının da yer değiştirmesi gerektiğinin göstermektedir. Hızlı olan bu değişim, canlıların yer değiştirme kabiliyetleri ile değerlendirilmelidir. Bazı türlerin bu değişime daha hızlı cevap verebileceği ve uyum sağlayacağı anlaşılmakta, bazı türlerin ise daha pasif kalacağı ve sonuç olarak canlı uyumu, türlerin yer değiştirme-göç etme kabiliyetleri ile orantılı olarak işleyecektir. 
Kültür bitkilerinin durumu ise, tarımsal faaliyeti yürüten bireylerin değişime tepkilerine ve yönetimlerin alacağ 1 tedbirlere göre şekillenecektir.

5-Biyom ve çevresel ortam değişimi, sadece sıcaklık artışı ile paralel olarak değişmemekte, yağış ve nemlilik koşullarındaki değişimlerle şekillenmektedir. 2061-2080 döneminde Türkiye'nin bir kısmında oluşan yağış artışları, 2041-2060 döneminde 1sınmaya bağlı değişimleri geriletmekte ve değişen ortamları tekrar günümüz koşullarına çevirmektedir. Fakat bu geri dönüşüm, 1sınma kaynaklı değişimin belli bir oranında-şiddetinde etkili olmakta, belli bir sıcaklık artışından sonra geri dönüşüm için daha yüksek yağış artışlarına ya da sıcaklık düşüşüne gereksinim duyulacağı anlaşılmaktadır.

\section{Notlar}

1: Holdridge ekolojik bölgeleri, üç farklı tanımlama içermekte, bu çalışmada her bir sınıf bir kod ile temsil edilmiştir. Kodlama sistemi, 5 basamaktan oluşmakta, soldan ilk sayı, yükselti ekolojik katı, sonraki iki sayı nemlilik sınıfını ve sağdaki 2 sayı ise biyomu vermektedir. Bu kodlar şöyledir. Yükselti ekolojik katları, 1-Tropikal, 2-Alçak irtifa, 3-Daüönü, 4-Dağlık, 5-Yarıalpin, 6-Alpin, 7-Karlı kat. Nemlilik bölgeleri, 01-Tam doygun, 02-Çok doygun, 03-Yarı Doygun, 04-Aşırı nemli, 05-Çok nemli, 06Nemli, 07-Yarı Nemli, 08-Yarı kurak, 09-Kurak, 10-Çok kurak, 11-Aşırı kurak, 12-Kavruk. Biyomlar, 01-Çöl, 02-Çöl çalılığ1, 03-Kurak çalılık, 04-Dikenli çalılık, 05-Dikenli step, 06-Step, 07-Çok Kurak orman, 08-Kurak orman, 09-Nemli orman, 10Dağlık nemli orman, 11-Islak orman, 12-Dağlık 1slak orman, 13-Yağmur orman1, 14-Dağl1k yağmur orman1, 15-Kurak tundra, 16-Nemli tundra, 17-Ilsak tundra, 18-Yağmurlu Tundra, 19-Soğuk Çöl, 20-Buzul

\section{Teșekkürler}

Yazar, çalışmayı okuyarak, değerlendiren ve eleştirilerde bulunarak katkı sağlayan Mehmet Özcanlı ve Ali Uğur Özcan ile makale hakemlerine teşekkürlerini sunmaktadır. 
To cite: Y1lmaz, E. (2021). Current and Future Holdridge Ecological Zones for Turkey Using High Resolution ERA-Interim and HadGEM2-CC Model Data, Coğrafi Bilimler Dergisi/ Turkish Journal of Geographical Sciences, 19(1), 29-60, doi: 10.33688 /aucbd.778259.

Coğrafi Bilimler Dergisi

Turkish Journal of Geographical Sciences

e-ISSN:1308-9765

Current and Future Holdridge Ecological Zones for Turkey Using High Resolution ERA-Interim and HadGEM2-CC Model Data

Erkan Y1lmaz*a,

Accepted: 08.01.2021

\section{EXTENDED ABSTRACT}

\section{Introduction}

The existing studies that have been conducted on Holdridge ecological zones (HEZ) in Turkey (Tatli and Dalfes, 2016; Tatl1, 2017; Tekin, Tatlı and Koç, 2018) have been station-based, and lack detailed information on regional borders. Although the HEZ borders have been determined on the global scale (Leemans, 1990), these are of low resolution and the details of these borders do not represent Turkey.

Total monthly precipitation and average monthly temperature data produced by Karger et al. (2017) has been used in this study to determine Turkey's current HEZ border details. Approximately 1 $\mathrm{km}$ resolution data sets have been used for this study. Turkey is represented by 800 thousand data points, HEZ altitude-latitude belts, humidity regions, and biome boundaries of the integrated HEZ have been obtained. Current HEZ regions are obtained for the 1979-2013 period and compared to future data based on the HadGEM2-CC model and RCP 4.5 scenario for the 2041-2060 and 2061-2080 periods.

\section{Methodology}

Total annual precipitation, biological temperature (BS), and potential evapotranspiration rate (PEO) were used (Holdridge, 1947) in order to create HEZ, HEZ classification has been made by placing the annual total precipitation (ATP) and PEO values on a triangle graphic. ATP and PEO data are given logarithmically, and the data belonging to meteorology field stations have been placed on the graph, so that the definition was made. Nearly 2.5 million-point data has been used in this study, and each data point has been included in this graph to determine the ecological region. For this purpose, the triangle graphic was digitized and converted into a map with each point defined.

The triangle graphic has been rotated by $150^{\circ}$ counterclockwise to bring the intersection of the abscissa (PEO) and the ordinate axis (ATP) to the 0,0 point of the plane, and a coordinate plane has been formed, where the PEO value forms the $\mathrm{X}$ axis and ATP forms the $\mathrm{Y}$ axis. When using this plane, the base 2 logarithm of both variables was used. However, in order to determine 0 for both values using $\log 2 \mathrm{PEO}, \log 20.125$ for $\mathrm{PEO}$ of 0.125 shown as $\mathrm{X} 1=0$, a point with a PEO ratio of 0.25 was represented with X1 $=1$. Similarly, by applying the formula $\log 2$ ATP $-\log 262.5$ for the ATP value, a place with $62.5 \mathrm{~mm}$ precipitation was represented as $\mathrm{Y} 1=0$, and a place with an ATP value of 125 was represented

\footnotetext{
* Corresponding Author: eryilmaz@ankara.edu.tr

aAnkara University, Department of Geography, Ankara/Turkey, http://orcid.org/ 0000-0002-3821-3648.
} 
as $\mathrm{Y} 1=1$. Subsequently, in order to determine the location of each point, a 60-degree slip ground was formed, with $\mathrm{X}=\sin 30 \mathrm{Y} 1+\mathrm{X} 1$ for each $\mathrm{X}$ value, and $\mathrm{Y}=\cos 30 \mathrm{Y} 1$ for each $\mathrm{Y}$ value, so that the Holdridge coordinates of each meteorology field station were determined. In this coordinate system, according to the reference points, the biomes, altitude belts, and humidity classes have also been defined with (by?) separate areas. The points placed on the coordinate plane have been used spatially, so that HEZ definitions are made for each point to complete the operations. Details of the method are presented at http://geography.humanity.ankara.edu.tr/turkiye-iklim-arastirmalari/ web page.

\section{Result and Discussion}

Six HEZ altitudinal zones have defined in Turkey. These can be listed as premontane, lower montane, montane, subalpine, alpine, and nival. Premontane condition areas defined in the Southeastern Anatolia Region lowlands, grabens and flood plains of the Aegean Region cover more than $7 \%$ of Turkey. The lower-montane areas that encircle the premontane areas are largely found in the Southern Anatolia, Aegean, Mediterranean, and Marmara Regions. They are also defined in the coastal areas of the Black Sea, lowlands of the Yeşilırmak and Kızılırmak valleys, and the depression of the Upper Fırat Subregions. Both premontane and lower-montane areas are expanding according to future climate model data for the 2041-2060 and 2061-2080 periods.

The montane belt, the largest zone in Turkey, covers most of the Eastern Anatolia Regions, Taurus and Black Sea Mountains, and high parts of the Central Anatolia Region and Inner Aegean and Yildiz Mountain Subregions. This belt area is modeled to contract in the 2041-2060 period. The subalpine belt covers the higher parts of the mountains of Eastern Anatolia and Black Sea Regions. While the alpine belt is defined in the Mediterranean, Central, and Eastern Anatolian and Black Sea Regions, the nival belt is defined only in the higher parts of Ararat.

According to the ERA-Interim data, semi-arid, sub-humid, humid, per-humid, super-humid, semi-saturated, sub-saturated, and saturated fields have been defined in Turkey. Turkey has no arid zones in its current conditions; although, climate model data shows that they will be formed in the Southeastern Anatolia Region and the southern part of the Iğdır plains after 2040. In Turkey, semi-arid zones are located in the Central and Southern Anatolian Regions while sub-humid zones form most of the Marmara, Aegean Mediterranean, Southern and Central Anatolian Regions. Sub-humid areas will expand in 2041-2060 and 2061-2080 periods according to HadGEM2-CC model data. Humid areas located in the Black Sea, Mediterranean, and Eastern Anatolian Regions will be narrowed per the model data in the 2041-2060 period. Per-humid, super humid, semi-saturated, and sub-saturated areas are located only in the Black Sea and Eastern Anatolian region mountains in the current climatic conditions. These four zones will also be narrowed according to the HadGEM2-CC climate model data. 

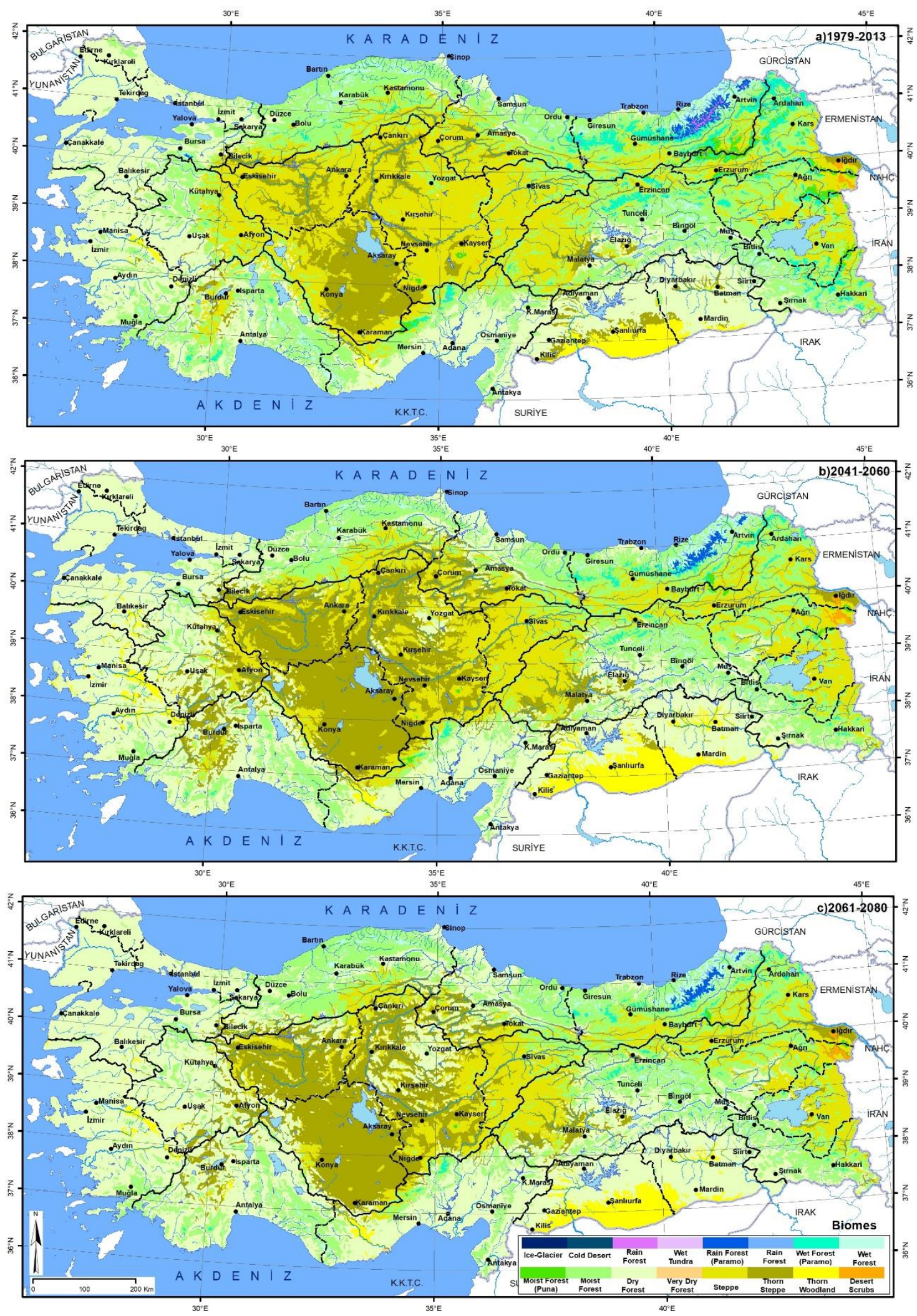

Figure 1. Biomes of Turkey by different periods. 
Today, the most arid biome in Turkey is the desert scrubs; this biome is defined in the Doğubeyazıt and Iğdır Plains (Figure 1). According to HadGEM2-CC model data, the biome will expand in the 2041-2060 period. The thorn woodland biome is defined in the Southeastern Anatolian Region, the depressions of the Southern Marmara and Aegean far from the sea, and Diyarbakır and Mut Basins. These areas will expand during the 2041-2060 period; even if it shrinks during the 2061-2080 period, it will cover an area that is almost double of its current size.

The thorn step biome, known as the "steppe with trees" in Turkish literature, is characterized in the Central Anatolian steps. According to future climate models, this biome will expand in the 20412060 period and cover the eastern part of the Central Anatolian Region. Step biome is located in the high plateau of the Eastern Anatolian Region, the Uzunyayla Plateau, and eastern part of the Lake Van basin. According to the future climate model, this biome area is contracting and changing to a thorn step area. Very dry forests are not defined in Turkey under current climatic conditions, while this biome does develop per analysis of the climate model data for the 2041-2060 period in the Silifke Delta.

Moist and wet/rain forest biomes will contract during the 2041-2060 and 2061-2080 periods. In Turkey, while the wet forest biome has been defined in the Southeastern Taurus Mountains, Teke and Taşeli Plateus, Köroğlu, Küre, Eastern Black Sea Mountains, and Uludağ, the rain forest biome is defined only in the higher parts of the Eastern Black Sea Mountains.

Tundra biome is located in the Black Sea Mountains, Aladağlar (Niğde province), the Keşiş Mountains in Eastern Anatolian Region, and the higher parts of the volcanic cone of Süphan, Erciyes, and the Ararat Mountains. Cold desert is defined in the high mountains of the Eastern Anatolian and Black Sea Regions $\left(15 \mathrm{~km}^{2}\right)$. The ice-glacial area covers $9 \mathrm{~km}^{2}$ only at Ararat. The glacial area (cold desert + ice + glacial) is expected to disappear during the 2061-2080 period due to rising temperatures.

The change matrix created for the present and the 2041-2060 period HEZ zones (Figure 2) has shown that a bit rate of the zones remained on the matrix diagonal (not displaced), and all classes moved. The change in the matrix did not occur in only one direction of the diagonal but exhibited displacement in both the directions. This change was not symmetrical; instead, an asymmetrical ellipse occurred. In the change matrix, according to the characteristics of the obtained codes, the movement to the right and down shows an increase in precipitation and decrease in PEO value. It is understood that the zones have changed due to temperature increase as well as humidity values. While these zones moved, other zones have taken their place.

According to the HEZ classification, while the environmental conditions of 1979-2013 are constantly expanding in the Mediterranean and Aegean coasts over the periods of 2041-2060 and 20612080, the plateau and high-mountainous conditions of the Central and Eastern Anatolia regions are constantly decreasing. 


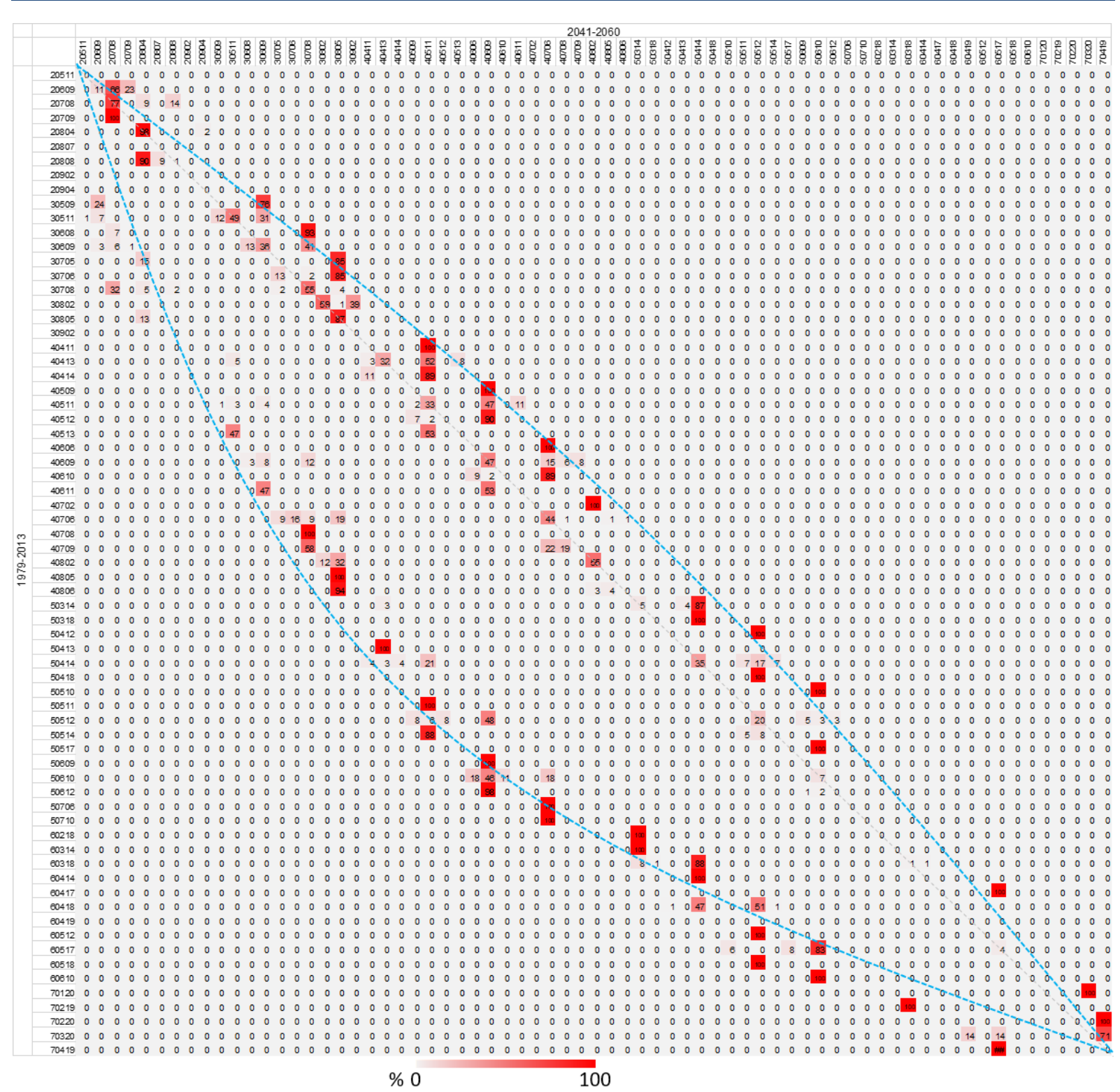

Figure 2. HEZ change matrix for the 1979-2013 and 2041-2060 periods.

\section{Conclusions}

In this study, enhanced resolution ( 1 km) versions of the ERA-Interim data for 1979-2013 and HADGEM2-CC model data for 2041-2060 and 2061-2080 periods produced by Karger et al. (2017) were used, and current and possible future HEZ classifications of Turkey and zone boundaries were investigated. A fast and safe HEZ definition technique that can be used in other climate classifications has also been developed using a geocoding-spatial join by using geographic information systems software. As a result of the analysis, the following can be concluded:

Depending on the temperature increase in the 2041-2060 and 2061-2080 periods, while premontane and lower-montane areas are expanding, montane, subalpine, alpine, and nival environments are narrowing. 
According to HEZ classification, there is no dry area in Turkey in the current climate; however, it will occur in the 2041-2060 period. While arid areas expand, wet areas will contract in the 2041-2060 period.

While desert scrub, thorny woodland, and thorn steppes are expanding in the 2041-2060 period and narrowing in the 2061-2080 period, steppe areas are constantly decreasing, arid forests are constantly expanding, and very-arid forest areas appear after the 2041-2060 period. While moist, wet/rain forests are narrowing in the 2041-2060 period and expanding in the 2061-2080 period, cold desert and tundra areas in Turkey will continuously contract, and glacier fields will be eliminated during the 2061-2080 period.

Overall, while the hot-dry environmental conditions in the south of Turkey and the coast are expanding, high mountain, cold-cool environmental conditions are narrowing. Biome and environmental conditions not only change in parallel with the increase in temperature but also are affected by changes in precipitation and humidity.

\section{Referanslar/References}

Arslan, E. S., Örücü, K. Ö. (2019). Present and future potential distribution of the Pinus Nigra Arnold. and Pinus Sylvestris L. using Maxent model. International Journal of Ecosystems and Ecology Science (IJEES), 9(4), 787-798. doi:10.31407/ijees9425.

Atalay, İ. (2008). Ekosistem Ekolojisi. İzmir: META Basım Matbaacılık Hizmetleri.

Baydar, A., Kanber, R. (2012). Effects of climatic changes on cotton production. Toprak Su Dergisi, 1(1), 47-54. doi:10.21657/tsd.55464.

Bozkurt, D., Sen, O. L. (2013). Climate change impacts in the Euphrates-Tigris Basin based on different model and scenario simulations. Journal of Hydrology, 480, 149-161. doi:10.1016/j.jhydrol.2012.12.021.

Çiner, A. (2003). Türkiye'nin Güncel Buzulları ve Geç Kuvaterner Buzul Çökelleri. Türkiye Jeoloji Bülteni, 46(1), 55-78.

Çoban, H. O., Örücü, Ö. K., Arslan, E. S. (2020). Maxent modeling for predicting the current and future potential geographical distribution of Quercus Libani Olivier. Sustainability (Switzerland), 12(7), 1-17. doi:10.3390/su12072671.

Dee, D. P., Uppala, S. M., Simmons, A. J., Berrisford, P., Poli, P., Kobayashi, S., ... Vitart, F. (2011). The ERA-Interim reanalysis: Configuration and performance of the data assimilation system. Quarterly Journal of the Royal Meteorological Society, 137(656), 553-597. doi:10.1002/qj.828.

Demir, İ., Kılıç, G., Çoşkun, M. (2008). Precis bölgesel iklim modeli ile Türkiye için iklim öngörüleri: HaDAMP3 SRES A2 senaryosu. IV. Atmosfer Bilimleri Sempozyumu, Bildiriler Kitabı, Bildiriler, 365-373.

Deveci, H., Konukcu, F., Altürk, B. (2019). İklim değişikliğinin Trakya Bölgesi’nde buğday yetiştirilen toprağın nem profiline etkisinin belirlenmesi. Journal of Tekirdag Agricultural Faculty, 16(2), 201-218. doi:10.33462/jotaf.543103.

Erinç, S. (1965). Yağış müessiriyeti üzerine bir deneme ve yeni bir indis. İstanbul: İstanbul Üniversitesi, Edebiyat Fakültesi, Coğrafya Enstitüsü Yayınları.

Erinç, S. (1949). The climates of Turkey according to Thornthwaite's classifications. Annals of the Association of American Geographers, 39(1), 26-46. doi:10.1080/00045604909351994.

Fick, S. E., Hijmans, R. J. (2017). WorldClim 2: new 1-km spatial resolution climate surfaces for global land areas. International Journal of Climatology, n/a-n/a. doi:10.1002/joc.5086.

Gönençgil, B., Sarıgül, O. (2018). Peltier'e göre Türkiye'nin morfojenetik bölgelerinin belirlenmesi. TÜCAUM 30. Yll Uluslararası Coğrafya Sempozyumu içinde (ss. 121-137). Ankara.

Gorguner, M., Kavvas, M. L., Ishida, K. (2019). Assessing the impacts of future climate change on the hydroclimatology of the Gediz Basin in Turkey by using dynamically downscaled CMIP5 projections. Science of the Total Environment, 648, 481-499. doi:10.1016/j.scitotenv.2018.08.167.

Güngör, T. (2019). Belirli iklim sınıflandırmalarının Türkiye için karşılaştırmalı analizi. Ankara Üniversitesi, Sosyal Bilimler Enstitüsü, Yayımlanmamış Yüksek Lisans Tezi. 
Gürkan, H., Arabac1, H., Demircan, M., Eskioğlu, O., Şensoy, S., Yazici, B. (2016). GFDL-ESM2M modeli temelinde RCP4.5 ve RCP8.5 senaryolarına göre Türkiye için sıcaklık ve yağış projeksiyonları. Coğrafi Bilimler Dergisi, 14(2), 77-88. doi:10.1501/Cogbil_0000000174.

Hepbilgin, B., Koç, T. (2017). HadGEM2-ES/RegCM4.3.4 küresel/bölgesel model verilerine göre Kaz Dăğ ve yakın çevresinin yağışlarında olası değişiklikler (2000-2099). Türk Coğrafya Dergisi, (69), 39-46. doi:10.17211/tcd.309311.

Hijmans, R. J., Cameron, S. E., Parra, J. L., Jones, P. G., Jarvis, A. (2005). Very high resolution interpolated climate surfaces for global land areas. International Journal of Climatology, 25(15), 1965-1978. doi:10.1002/joc.1276.

Holdridge, L. R. (1947). Determination of world plant formations from simple climatic data. Science, 105(2727), 367-368. doi:10.1126/science.105.2727.367.

Holdridge, L. R., Joseph, A. T. (1967). Life Zone Ecology with Photographic Supplement Prepared. Tropical Science Center. Costa Rica.

Kapur, B., Koç, M., Özekici, B. (2012). Artan CO2 ve küresel iklim değişikliğinin Çukurova Bölgesinde buğday verimliliği üzerine etkileri. Ç.Ü Fen ve Mühendislik Bilimleri Dergisi, 28(4), 152-162.

Karaoğlu, M. (2018). Iğdır-Aralık’ta rüzgar erozyonu çalışmaları. Journal of Agriculture, 1(2), 25-38.

Karger, D. N., Conrad, O., Böhner, J., Kawohl, T., Kreft, H., Soria-Auza, R. W., ... Kessler, M. (2017). Climatologies at high resolution for the earth's land surface areas. Scientific Data, 4(1), 1-20. doi:10.1038/sdata.2017.122.

Kattsov, V., Federation, R., Reason, C., Africa, S., Uk, A. A., Uk, T. A., ... Uk, A. S. (2013). Evaluation of climate models. Climate Change 2013 the Physical Science Basis: Working Group I Contribution to the Fifth Assessment Report of the Intergovernmental Panel on Climate Change, 9781107057, 741-866. doi:10.1017/CBO9781107415324.020.

Köppen, W., Geiger, R. (1954). Klima der erde (climate of the earth) wall map 1:16 Mill. Gotha: Klett-Perthes.

Kottek, M., Grieser, J., Beck, C., Rudolf, B., Rubel, F. (2006). World map of Köppen-Geiger climate classification updated. Meteorologische Zeitschrift, 15, 259-263. doi:10.1127/0941-2948/2006/0130.

Leemans, R. (1990). Possible changes in natural vegetation due to a global warming. Global data sets collected and compiled by the Biosphere Project, Working Paper (C. Working Pa). Laxenburg, Austria: IIASA. doi:10.1017/cbo9780511525537.030.

Lugo, A. E., Brown, S. B., Dodson, R., Smith, T. S., Shugart, H. H. (1999). The Holdridge life zones of the conterminous United States in relation to ecosystem mapping. Journal of Biogeography. doi:10.1046/j.1365-2699.1999.00329.x.

Mert, A., Özkan, K., Şentürk, Ö., Negiz, M. G. (2016). Changing the potential distribution of Turkey oak (Quercus cerris L.) under climate change in Turkey. Polish Journal of Environmental Studies, 25(4), 1633-1638. doi:10.15244/pjoes/62230.

OGM. (2012). Orman Atlası. Ankara: Orman ve Su İşleri Bakanlığı, Orman Genel Müdürlüğü.

Önol, B., Semazzi, F. H. M. (2009). Regionalization of climate change simulations over the Eastern Mediterranean. Journal of Climate, 22(8), 1944-1961. doi:10.1175/2008jcli1807.1.

Ozturk, T., Altinsoy, H., Türkeş, M., Kurnaz, M. L. (2012). Simulation of temperature and precipitation climatology for the Central Asia CORDEX domain using RegCM 4.0. Climate Research, 52(1), 63-76. doi:10.3354/cr01082.

Peel, M. C., Finlayson, B. L., Mcmahon, T. A. (2007). Updated world map of The Koppen-Geiger climate classification. Hydrol. Earth Syst. Sci. Discuss., 4, 439-473.

Raja, N., Aydin, O., Türkoğlu, N., Çiçek, İ. (2019). A reconstruction of Turkey’s potential natural vegetation using climate indicators. Journal of Forestry Research, 30(6), 2199-2211. doi:10.1007/s11676-018-0855-7.

Rohli, V. R., Vrga, A. J., Rohli, R. V. (2018). Climatology. Burlington: Jones\&Barlett Learning.

Sarıkaya, M. A. (2011). Türkiye'nin Güncel Buzulları. İ. D. Ekinci (Ed.), Fiziki Coğrafya Araştırmaları: Sistematik ve Bölgesel (Prof.Dr. Mehmet Yıldız Hoşgören'e armağan kitabı) içinde . İstanbul.

Sarıkaya, Mehmet Akif, Çiner, A., Zreda, M. (2011). Quaternary glaciations of Turkey. Developments in Quaternary Science, 15(December), 393-403. doi:10.1016/B978-0-444-53447-7.00030-1.

Sarıkaya, O., Karaceylan, I. B., Sen, I. (2018). Maximum entropy modeling (maxent) of current and future distributions of Ips mannsfeldi (Wachtl, 1879) (curculionidae: Scolytinae) in turkey. Applied Ecology and Environmental Research, 16(3), 2527-2535. doi:10.15666/aeer/1603_25272535.

Şensoy, S., Ulupınar, Y. (2015). İklim sinuflandırmalart. http://212.174.109.9/FILES/iklim/iklim_siniflandirmalari.pdf, 29.06.2016. Ankara. 
Sezer, İ. L. (1988). İklim ve vejatasyon sinıflandırması konusunda yeni bir indis denemesi. Ege Coğrafya Dergisi, 4, 161-201.

Tatli, H., Dalfes, H. N. N. (2016). Defining Holdridge's life zones over Turkey. International Journal of Climatology, 36(11), 3864-3872. doi:10.1002/joc.4600.

Tatl1, H. (2017). Classification of the Köppen and Holdridge life zones with respect to the climate scenarios- Rcp4.5 over Turkey. 8th Atmospheric Sciences Symposium - 01-04 November 2017, 651-657.

Taylor, L. R., Myers, A. A., Giller, P. S. (1989). Analytical Biogeography. The Journal of Animal Ecology (C. 58). doi:10.2307/5151.

Tekin, M. K., Tatlı, H., Koç, T. (2018). Türkiye'deki yaşam-bölgelerinin Holdridge yaşam-zon yöntemi ile belirlenmesi. TÜCAUM 30. Yıl Uluslararası Coğrafya Sempozyumu içinde (ss. 713-722).

Thornthwaite, C. W. (1948). An approach toward a rational classification of climate. Geographical Review, $38(1), 55$. doi: $10.2307 / 210739$

Trewartha, G. T. (1968). An Introduction to Climate. New York: McGraw-Hill.

Türkeş, M. (2013). Biyocoğrafya; Bir Paleocoğrafya ve Ekoloji Yaklaşımı. İstanbul: Kriter Yayınevi.

Turp, M. T., Tuğba Öztürk, Türkeş, M., Kurnaz, M. L. (2014). Investigation of projected changes for near future air temperature and precipitation climatology of Turkey and surrounding Regions by using the regional climate model RegCM4.3.5. Ege Coğrafya Dergisi, 23(1), 1-24.

Ustaoglu, B., Karaca, M. (2014). The effects of climate change on spatiotemporal changes of Hazelnut (Corylus Avellana) cultivation areas in the Black Sea Region, Turkey. Applied Ecology and Environmental Research (AEER), 12(2), 309324.

Walas, Ł., Sobierajska, K., Ok, T., Dönmez, A. A., Kanoğlu, S. S., Dagher-Kharrat, M. B., ... Boratyński, A. (2019). Past, present, and future geographic range of an oro-Mediterranean Tertiary relict: The juniperus drupacea case study. Regional Environmental Change, 19(5), 1507-1520. doi:10.1007/s10113-019-01489-5.

Yılmaz, E., Çiçek, İ. (2016). Türkiye Thornthwaite iklim sınıflandırması. Journal of Human Sciences, 13(3), 3973-3993. doi:10.14687/jhs.v13i3.3994.

Yılmaz, E., Çiçek, İ. (2018). Türkiye'nin detaylandırılmış Köppen-Geiger iklim bölgeleri. İnsan Bilimleri Dergisi, 15(1), 225242. 